\title{
Ionic Flux Contributions to Neocortical Slow Waves and Nucleus Basalis-mediated Activation: Whole-cell Recordings in vivo
}

\author{
Raju Metherate and John H. Ashe \\ Departments of Neuroscience and Psychology, University of California, Riverside, California 92521
}

Slow, rhythmic membrane potential $\left(\boldsymbol{V}_{\mathrm{m}}\right)$ fluctuations occur spontaneously in cortical neurons of urethane-anesthetized rats, and likely underlie EEG activity in the same low-frequency (1-4 Hz or $\delta$ ) range. Nucleus basalis (NB) stimulation elicits neocortical activation, simultaneously modifying $V_{m}$ and EEG fluctuations, by way of cortical muscarinic $\mathrm{ACh}$ receptors (Metherate et al., 1992). To investigate the nature of spontaneous fluctuations and their modification by NB stimulation, we have obtained intracellular recordings from auditory cortex using the whole-cell recording technique in vivo. Spontaneous $V_{m}$ fluctuations appeared to contain three components whose polarity and time course resembled the EPSP, putative $\mathrm{Cl}^{-}$-mediated IPSP, and putative $\mathrm{K}^{+}$-mediated, long-lasting IPSP elicited by thalamic stimulation. The spontaneous, long-lasting hyperpolarization, whose rhythmic occurrence appeared to set the slow-wave rhythm, was associated with an increased conductance that could shunt the thalamocortical EPSP. We hypothesized that spontaneous $V_{m}$ fluctuations arise from intermixed rapid depolarizations, rapid $\mathrm{Cl}^{-}$-mediated hyperpolarizations, and long-lasting, $\mathrm{K}^{+}$-mediated hyperpolarizations. NB-mediated cortical activation might then result from muscarinic suppression of $\mathrm{K}^{+}$permeability, allowing the rapid depolarizations and $\mathrm{Cl}^{-}$ fluxes to continue uninterrupted. Tests of this hypothesis showed that (1) intracellular blockade of $K^{+}$channels by rapid diffusion of $\mathrm{Cs}^{+}$from the recording pipette resulted in suppression of spontaneous, long-lasting hyperpolarizations, mimicking the effect of NB stimulation, and reducing shunting of the thalamocortical EPSP; (2) effects of $\mathrm{Cs}^{+}$and NB stimulation suggested overlapping, or converging, mechanisms of action; however, there were important differential effects on the spontaneous, long-lasting hyperpolarizations and the $\mathrm{K}^{+}$-mediated IPSP; and (3) modifying $\mathrm{Cl}^{-}$- fluxes with intracellular picrotoxin or high intracellular $\mathrm{Cl}^{-}$concentrations resulted in spontaneous and NB-elicited large-amplitude depolarizations.

We conclude that spontaneous, long-lasting hyperpolarizations are $\mathrm{K}^{+}$fluxes, but are not "spontaneous" $\mathrm{K}^{+}-\mathrm{me}$ diated IPSPs. Since NB-mediated reduction of spontaneous hyperpolarizations implies muscarinic suppression of a $\mathrm{K}^{+}$ conductance, the spontaneous hyperpolarizations more likely

\footnotetext{
Received Mar. 1, 1993; revised May 21, 1993; accepted June 17, 1993

We thank Dr. A. Agmon for helpful advice on the whole-cell recording procedure. This work was supported by the National Science Foundation (IBN 9008818 IBN 9118872).

Correspondence should be addressed to J. H. Ashe, Ph.D., Departments of Neuroscience and Psychology -075, University of California, Riverside, CA 92521.

Copyright $\odot 1993$ Society for Neuroscience $0270-6474 / 93 / 135312-12 \$ 05.00 / 0$
}

result from the calcium-activated $K^{+}$current, $I_{k(c a)}$. Finally, $\mathrm{Cl}$ - fluxes form an important component of activated $\boldsymbol{V}_{\mathrm{m}}$ fluctuations that acts to restrain excessive depolarization.

IKey words: plasticity, EEG, auditory neocortex, nucleus basalis, intracellular, arousal, whole-cell recording, $\mathrm{ACh}$, muscarinic]

Ensembles of neocortical neurons generate patterns of synchronized activity, observable on a macroscopic level as the EEG, that vary greatly with behavioral state. Two important EEG patterns are large-amplitude, slow waves ( $\delta$ waves) and smallamplitude, fast waves (EEG desynchronization, or activation) that characterize deep sleep and wakefulness, respectively (for reviews, see Buzsaki et al., 1988; Vanderwolf, 1988; Steriade et al., 1990). Despite numerous studies correlating different EEG patterns with different behaviors and pathologies, the cellular bases of the EEG and its modifications remain unclear (for reviews, see Creutzfeldt, 1974; Vanderwolf, 1988).

A mechanistic understanding of synchronized cortical activity has been hampered by its absence, for the most part, in in vitro brain slices (notable exceptions being during pharmacological manipulations; e.g., work reviewed by Schwartzkroin and Wheal, 1984). However, in vitro studies have generated important information regarding cortical local circuits, largely by focusing on stimulus-evoked activity, and identifying the neurotransmitters, receptors, and ion species involved. For example, afferent stimulation in many neocortical regions elicits a stereotypic synaptic response consisting of a fast EPSP followed by an early, fast IPSP (e-IPSP) and a late, slow IPSP (I-IPSP) (Connors et al., 1982, 1988; Avoli, 1986; Cox et al., 1992). The IPSPs are mediated by the neurotransmitter GABA binding to $\mathrm{GABA}_{\mathrm{A}}$ and $\mathrm{GABA}_{\mathrm{B}}$ receptors, respectively, which gate increased membrane conductances to $\mathrm{Cl}^{-}$and $\mathrm{K}^{+}$ions, respectively (Gahwiler and Brown, 1985; Connors et al., 1988; Cox et al., 1992; Sieghart, 1992). Thus, detailed information exists regarding cortical local circuits that can be used to understand the behavior of larger neural systems.

To identify mechanisms of cortical plasticity, we have been investigating cholinergic modification of neuronal excitability in auditory cortex, using both in vivo and in vitro approaches (Weinberger et al., 1990; Cox et al., 1992; Metherate et al., 1992; Metherate and Ashe, 1993). Recently, we have shown that chemical or electrical stimulation of the nucleus basalis (NB) can modify ongoing, synchronized cortical activity ( $V_{m}$ fluctuations and EEG slow waves) by an action at cortical muscarinic cholinergic receptors (Metherate et al., 1992). To better understand the cellular basis of spontaneous fluctuations and their modification by NB stimulation, we have obtained intracellular recordings from the in vivo auditory cortex using a variant of 
the whole-cell recording (WCR) technique (Hamill et al., 1981). The advantage of the WCR technique is that it enables highresolution recordings and, importantly, permits systematic manipulation of the intracellular environment (Pusch and Neher, 1988). Our goal was to characterize $V_{m}$ fluctuations, (1) by comparing them to synaptic potentials elicited by thalamic stimulation, and by extension, to ionic mechanisms identified in vitro, and (2) by the effects of pharmacological agents introduced intracellularly, via the recording pipette.

\section{Materials and Methods}

Details of the surgical preparation and electrical stimulation were as reported previously (Metherate and Ashe, 1993). Briefly, male rats (Sprague-Dawley, 250-350 gm) were anesthetized with urethane (1.5 $\mathrm{gm} / \mathrm{kg}$, i.p.), supplemented as needed $(0.2 \mathrm{gm} / \mathrm{kg})$ to maintain areflexia and slow-wave EEG activity, and placed in a stereotaxic apparatus on a heating pad (rectal temperature maintained at $37^{\circ} \mathrm{C}$ ). Tracheal cannulation, lumbar suspension, and drainage of the cisterna magna minimized brain pulsations due to respiration and blood pressure fluctuations. Craniotomies over auditory cortex, thalamus, and frontal cortex allowed for placement of recording and stimulation electrodes. For electrical stimulation of the NB, bipolar electrodes were placed at (in $\mathrm{mm}$ from bregma; Paxinos and Watson, 1986) AP -1.4 to -1.8 , ML 2.0, depth $\sim 6.4$ from the pia. Stimulating electrodes were also placed in the medial geniculate body (MG) of the thalamus (AP - 5.8, ML 2.8, depth 25.4). Electrical stimuli consisted of 0.1 -msec-duration constant current pulses, generally $100-500 \mu \mathrm{A}$, delivered singly to the $\mathrm{MG}$, or as a train to the NB (typically $20-100$ pulses at $200 / \mathrm{sec}$ ). These stimulus loci and parameters are optimal for electrical or chemical stimulation of the cholinergic NB projection to auditory cortex, and for electrical stimulation of the MG projection to auditory cortex (Metherate et al., 1992; Metherate and Ashe, 1993). Experiments were terminated by anesthesia overdose.

Recording micropipettes were pulled on a horizontal puller (P-87, Sutter Instruments, Novato, CA) in three stages from borosilicate glass (1.5 mm o.d., $0.8 \mathrm{~mm}$ i.d.; A-M Systems, Everett, WA). Micropipettes were more tapered than those typically used for patch-clamp studies (Hamill et al., 1981), and had a final outside tip diameter of about 2.5 $\mu \mathrm{m}$ and DC resistance of 4-6 M $\mathrm{M}$ when filled. Recording solutions, referred to as $\mathrm{K}^{+}$-based (or $\mathrm{Cs}^{+}$-based), consisted of (in $\mathrm{mM}$ ) $\mathrm{K}$-gluconate (Cs-gluconate), 120-125; $\mathrm{KCl}(\mathrm{CsCl}), 5 ; \mathrm{CaCl}_{2}, 1-2 ; \mathrm{MgCl}_{2}, 1-2$; ethylene glycol-bis( $\beta$-aminoethylether)- $N, N, N^{\prime}, N^{\prime}$-tetraacetic acid (EGTA), 10 ; and $N$-2-hydroxyethylpiperazine- $N^{\prime}-2$ ethanesulfonic acid (HEPES), 10 ; adjusted to $\mathrm{pH} 7.3$ with $\mathrm{KOH}(\mathrm{CsOH})$. To manipulate $\mathrm{Cl}^{-}$fluxes, picrotoxin was added to the recording solution, or additional $\mathrm{Cl}^{-}$was substituted for gluconate as indicated in the Results. Final osmolality was adjusted to about $260-270 \mathrm{mmol} / \mathrm{kg}$. Osmolality of cerebrospinal fluid obtained following cisternal puncture ranged from about 297 to $305 \mathrm{mmol} / \mathrm{kg}$. All drugs and chemicals were obtained from Sigma Chemical Co., St. Louis, MO.

Methods for obtaining whole-cell recordings (WCRs) were similar to those used in brain slices (Blanton et al., 1989) and in vivo (Pei et al., 1991; Ferster and Jagadeesh, 1992). Positive and negative pressure was applied to the rear of the pipette using a syringe connected via polyethylene tubing to the side port of the sealed electrode holder (Axon Instruments, Foster City, $\mathrm{C} \Lambda$ ). $\Lambda$ fter making a small cut in the dura, the electrode was inserted with positive pressure maintained to prevent blocking of the tip. Great care was taken to avoid blood or any debris that might adhere to the pipette tip. Similarly, each electrode could be used for only one penetration and one gigaohm seal. Once the electrode was in place, positive pressure was removed and the surface of the brain was covered with agar ( $4 \%$ in saline). The electrode was then slowly advanced with either no or low positive pressure applied, and with repeated presentation of constant current pulses $(100 \mathrm{pA}, 50 \mathrm{msec}, 1$ $\mathrm{Hz}$ ). The proximity of a cell membrane was indicated by a $10-20 \%$ increase in the voltage response to the current pulse, at which point any positive pressure was removed and gentle negative pressure applied. The voltage response gradually increased, even though the negative pressure was removed after several seconds, until a large voltage response indicated establishment of a gigaohm seal. This process could occur rapidly over $10-15 \mathrm{sec}$, or could take several minutes with suction applied intermittently. When the voltage response indicated a stable, 1-3 G $\Omega$ seal, a second gentle suction of slowly increasing intensity was

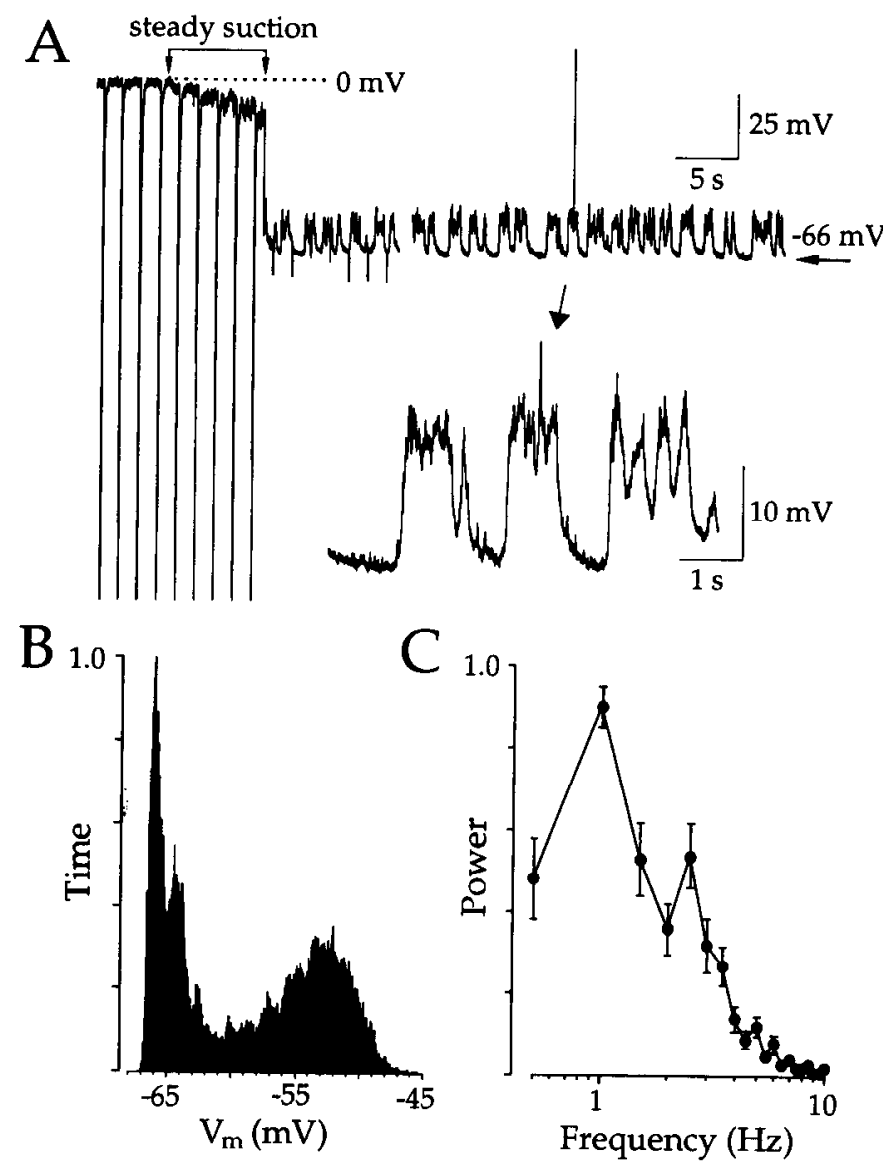

Figure 1. Spontaneous membrane potential fluctuations obtained during WCRs in vivo. $A$, Sample record initially shows gigaohm seal, evidenced by large, negative voltage responses to $1 / \mathrm{sec}, 100 \mathrm{pA}$ current pulses (current monitor not shown). After steady suction (hetween arrows), the underlying membrane ruptured, establishing the WCR configuration (note much smaller responses to current pulses). Current pulses were turned off (gap in record represents $10 \mathrm{sec}$ ), and stable $V_{m}$ fluctuations continued. Inset shows higher-resolution record, including spontaneously occurring spike (truncated). $B$, Histogram of $V_{m}$ versus time for the cell in $A$, constructed from $15 \mathrm{sec}$ of spontaneous activity. Bin width, $0.05 \mathrm{mV}$; time axis is normalized to peak value of histogram. Note two prominent peaks, one at about $-66 \mathrm{mV}$, reflecting the longlasting hyperpolarization, and a second, broader peak at about $-53 \mathrm{mV}$, produced by rapid fluctuations at depolarized levels. $C$, Mean $( \pm \mathrm{SE})$ power spectrum of 25 neurons with robust spontaneous $V_{m}$ fluctuations shows peak power near $1 \mathrm{~Hz}$. Individual spectra were normalized to peak value before averaging.

applied for several seconds, until the underlying patch of membrane ruptured to establish the WCR configuration (Fig. 1). In some cascs, the membrane ruptured spontaneously, due perhaps to an osmotic pressure difference between the cell interior and the pipette solution; no obvious distinctions were detected between WCRs obtained by either method.

Neural signals were recorded using an intracellular amplifier (Axoclamp 2A, Axon Instruments), viewed on an oscilloscope and chart recorder, and stored on magnetic tape (bandpass, $0-5 \mathrm{kHz}$ ). Following additional amplification, recordings were also digitized at $5-10 \mathrm{kHz}$ (MIO-16; National Instruments, Austin, TX) and stored on computer (Macintosh Quadra 900, Apple Computer, Cupertino, CA). Computer software was used to control the experiment (AxODATA, Axon Instruments) and for off-line analyses (AXOGRAPH, Axon Instruments). Power spectra were obtained using AXOGRAPH from 15-20 sec records of spontaneous activity that had been digitally filtered at $1 \mathrm{kHz}$. Rccordings in the bridge mode were not compensated for series resistance; thus, while voltage errors during passage of steady current through the recording electrode are likely to be only $5-10 \%$ (estimate based on difference 
Table 1. Properties of neurons in rat auditory cortex recorded using whole-cell or sharp microelectrode recording methods in vivo and in vitro

\begin{tabular}{lccr} 
& $\begin{array}{l}\text { Whole-cell recording } \\
\text { in vivo }\end{array}$ & $\begin{array}{l}\text { Sharp electrode } \\
\text { in vivo }\end{array}$ & $\begin{array}{c}\text { Sharp electrode } \\
\text { in vitro }\end{array}$ \\
\hline Baseline $V_{m}(\mathrm{mV})$ & $-64 \pm 1.4$ & $-66 \pm 1.7$ & $-75 \pm 1.2$ \\
$R_{i}(\mathrm{M} \Omega)$ & $152 \pm 10.3$ & - & $37 \pm 3.0$ \\
Spike threshold $(\mathrm{mV})$ & $-43 \pm 1.6$ & $-57 \pm 1.3$ & $-58 \pm 1.5$ \\
Spike amplitude & $>50 \mathrm{mV}, 63 \pm 3.2, n=17$ & $64 \pm 1.5$ & $72 \pm 1.3$ \\
$\quad(\mathrm{mV}$, from threshold) & $<40 \mathrm{mV}, 31 \pm 1.8, n=19$ & & \\
$n$ & $31-37$ & 27 & 50 \\
\hline
\end{tabular}

Values are mean $\pm \mathrm{SE}$.

${ }^{a}$ Data from Metherate and Ashe (1993); $R_{i}$ not measured.

${ }^{b}$ Data from Metherate et al. (1992).

between continuous and discontinuous current-clamp recordings), $V_{m}$ values are reported only when no steady current was passed (i.e., at the resting potential). In other cases, to measure the effect of steady current on $V_{m}$, the discontinuous current-clamp (DCC) mode of the amplifier was employed with switching frequencies of $8-10 \mathrm{kHz}$. Headstage voltage was monitored on a separate oscilloscope, to ensure adequate settling time

Evidence for rundown of spontaneous or thalamic-evoked activity was obtained in some experiments after 10-20 min of recording, and in others only after much longer periods of time. For example, spontaneous long-lasting hyperpolarizations lasted in some cases for over 1 hr, but in other cells began to dissipate within 10-15 min. Thalamicevoked synaptic responses were more stable over time, presumably due to greater resistance to the effects of rundown than spontaneous fluctuations. In six neurons, $\mathrm{Mg}$-adenosine 5'-triphosphate (Mg-ATP; 1 $\mathrm{mm}$ ) and Tris-guanosine $5^{\prime}$-triphosphate (Tris-GTP; 0.5-0.7 mM) were added to the pipette solutions; however, no appreciable differences in the monitored characteristics resulted. To minimize the possibility of artifactual findings due to rundown, the data presented here derive from the first $10 \mathrm{~min}$ of recording, except where noted. Membrane parameters such as baseline $V_{m}$, apparent input resistance $\left(R_{i}\right)$, and spike characteristics were determined within 1-2 min following rupture of the membrane. All mean values are \pm SEM.

\section{Results}

WCRs were obtained from 43 neurons in the auditory cortex of urethane-anesthetized rats. Recording sites lay in the superficial to middle layers of the cortex (mean depth, $470 \pm 29 \mu \mathrm{m}$ from the pia, typically $250-700 \mu \mathrm{m}$ ), and recording durations ranged from several minutes to over $1 \mathrm{hr}$. The sample recording in Figure $1 A$ initially shows a tight seal of approximately 2.3 $\mathrm{G} \Omega$ (typically $1-3 \mathrm{G} \Omega$ ) between the pipette and cell membrane, indicated by the large-amplitude responses to $100 \mathrm{pA}$ current pulses. Following rupture of the membrane patch by gentle, steady suction (arrows in Fig. $1 A$ ), the establishment of the WCR configuration is indicated by the appearance of a transmembrane potential and approximately 10 -fold smaller voltage responses to the $100 \mathrm{pA}$ current pulses. Note that slow, spontaneous $V_{m}$ fluctuations are immediately apparent, and that the spontaneous depolarizations can elicit action potentials. Following the convention used throughout this report, the largest $V_{m}(-66 \mathrm{mV}$ in Fig. $1 A$ ) is used to designate the baseline, or "resting," membrane potential.

Neuronal membrane parameters obtained during WCRs are shown in Table 1. For comparison, these are presented with data from two previous studies of rat auditory cortex conducted using conventional sharp microelectrodes. Baseline $V_{m}$ averaged $-64 \pm 1.4 \mathrm{mV}$, and measurements of $R_{i}$, obtained during longlasting hyperpolarizations for consistency, averaged $152 \pm 10.3$ M $\Omega$. However, since $R_{i}$ varied with $V_{m}$ fluctuations (see Fig. $2 B$ ), and since the long-lasting hyperpolarization likely reflects an active conductance (see below), this baseline measure is useful mainly for comparison, and is an underestimate of the resting $R_{i}$. Spontaneous action potentials arose from a threshold of -43 $\pm 1.6 \mathrm{mV}$ and, based on spike amplitude from threshold, ncurons could be divided into two distinct groups (Student's $t$ test, $p<0.001)$. The first group had spikes with amplitudes larger than $50 \mathrm{mV}$ (mean, $63 \pm 3.2 \mathrm{mV}$; range, $50-95 \mathrm{mV} ; n=17$ ), whereas the second had smaller spike amplitudes of $20-40 \mathrm{mV}$ (mean, $31 \pm 1.8 \mathrm{mV} ; n=19$ ). Thus, the first group of spike amplitudes resembled those obtained in a previous in vivo study of auditory cortex, conducted with conventional sharp microelectrodes (Table 1), whereas the second group did not. A further distinction was that cells with large spikes had lower input resistances $(117 \pm 15.2 \mathrm{M} \Omega)$ than did cells with small spikes (187 $\pm 13.6 \mathrm{M} \Omega ; p<0.01)$. The two groups of cells did not differ in terms of baseline $V_{m}$, spike threshold, distribution by cortical depth, or recording solution $\left(\mathrm{K}^{+}\right.$- or $\mathrm{Cs}^{+}$-based) $(p>0.05)$. One possibility, suggested by data from hippocampal pyramidal neurons (Wong et al., 1979; Poolos and Kocsis, 1990), is that smallamplitude spikes and high $R_{i}$ values reflect dendritic recordings, whereas recordings from cell bodies comprise the group with large spikes and lower $R_{i}$ values. Combined electrophysiological and morphological studies will be needed to resolve this issue.

\section{Spontaneous and MG-evoked subthreshold activity}

Slow, spontaneous $V_{m}$ fluctuations resembled those recorded with conventional sharp microelectrodes (Metherate et al., 1992). In 25 neurons exhibiting robust fluctuations, the $V_{m}$ varied over a $15-25 \mathrm{mV}$ range at a rate of about $0.5-3 \mathrm{~Hz}$ (Fig. 1). The fluctuations were dominated by the rhythmic recurrence of a long-lasting hyperpolarizing potential (duration of about 200$600 \mathrm{msec}$, measured from midway between the maximum and minimum $V_{m}$ amplitude). This potential peaked at $-72 \pm 1.6$ $\mathrm{mV}$; its long duration produced a peak near this value in the $V_{m}$ versus time histogram of spontaneous fluctuations for individual neurons (Fig. $1 B$ ). Note also that depolarized phases of slow $V_{m}$ oscillations contained rapid depolarizing and hyperpolarizing fluctuations (Fig. $1 A$, inset); these fluctuations contributed to a broader peak at depolarized levels in the $V_{m}$ versus time histogram (Fig. $1 B$, peak centered near $-53 \mathrm{mV}$ ). Power spectrum analysis of robust spontaneous fluctuations revealed a peak at $1.3 \pm 0.2 \mathrm{~Hz}$ (range of individual peak values, $0.5-$ $2.7 \mathrm{~Hz}$; Fig. $1 C$ ), again reflecting the influence of the long-lasting hyperpolarization. In three neurons $V_{m}$ fluctuations were absent 

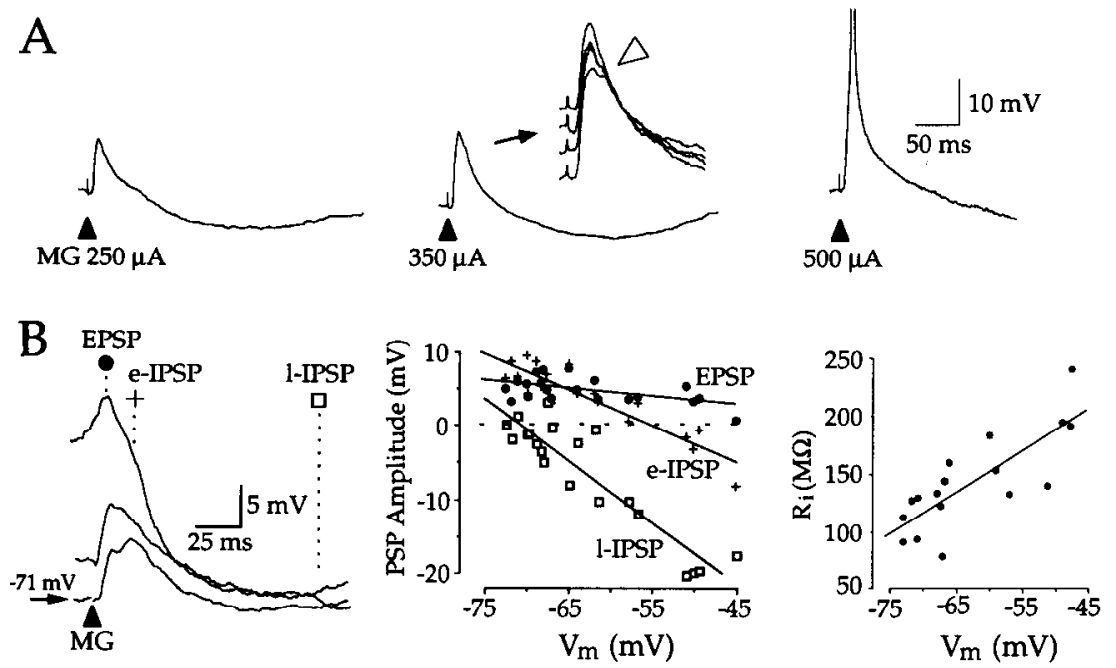

Figure 2. Cortical synaptic potentials elicited in $\mathrm{K}^{+}$-based recording solutions by stimulation of the MG thalamus. $A$, Increasing the stimulus intensity increased the amplitude of both the monosynaptic EPSP and the long-lasting l-IPSP. At the highest intensity (500 $\mu$ A), the EPSP elicited a spike (truncated). Records are averages of four responses, except response at $500 \mu \mathrm{A}$, which is a single trace. Inset over middle record depicts individual responses comprising the average, and indicates the presence of an intermediate potential (e-IPSP) at a latency of about 20 msec (open arrowhead). Baseline $V_{m}$ was $-60 \mathrm{mV}$, but records were taken during steady hyperpolarization to reduce spiking. $B$, Voltage dependence of EPSP, e-IPSP, and l-IPSP obtained by stimulating the MG during different phases of spontaneous $V_{m}$ fluctuations $(0.5 \mathrm{~Hz}$ stimulus rate). Sample traces (left panel) from different $V_{m}$ values show that response amplitudes varied as expected for synaptic potentials (except for slight shunting of the EPSP), and that the e-IPSP reversed polarity at an intermediate potential. Middle panel quantifies change of amplitude with $V_{m}$ of EPSP (solid circles; measured at latency of $9 \mathrm{msec}$, correlation coefficient $r=0.538$ ), e-IPSP (crosses; $22 \mathrm{msec}, r=0.907$ ), and l-IPSP (open squares; 123 msec, $r=0.919$ ). The basis for electrical shunting is shown in the right panel, which illustrates the change in $R_{i}$ during different phases of $V_{m}$ fluctuations in the same cell. $R_{i}$ was least during spontaneous, long-lasting hyperpolarizations, and its value could double at other times during spontaneous fluctuations.

$(<5 \mathrm{mV})$; these neurons were located relatively superficially (200 $\mu \mathrm{m}, 250 \mu \mathrm{m}$, and $376 \mu \mathrm{m})$. The remaining neurons $(n=$ 15) displayed $V_{m}$ fluctuations of intermediate $(9-15 \mathrm{mV}) \mathrm{am}$ plitude; these fluctuations resembled those in the majority of cells, but with less prominent long-lasting hyperpolarizations.

Electrical stimulation of the MG thalamus elicited in auditory cortex a short-latency EPSP $(\mathrm{n}=26)$ followed by a slower, 1-IPSP $(n=25$; Fig. 2A). The EPSP had an onset latency of $4.2 \pm 0.2$ msec, a latency to peak of $10 \pm 0.5 \mathrm{msec}$, and an amplitude varying from about 2 to $15 \mathrm{mV}$, depending on when it occurred during the spontaneous $V_{m}$ fluctuations (i.e., the EPSP was generally smaller during depolarized phases, and larger during hyperpolarized phases; Fig. $2 B$ ). The l-IPSP had a latency to peak of $127 \pm 8.2 \mathrm{msec}$, a duration of about $150-250 \mathrm{msec}$, and an amplitude varying from about 0 to $20 \mathrm{mV}$, again depending on the phase of $V_{m}$ fluctuations. In 10 of 26 cells, responses to $M G$ stimulation suggested the presence of an additional potential at a latency of $18-20 \mathrm{msec}$ (Fig. $2 A$, inset). Passage of steady depolarizing or hyperpolarizing current through the recording electrode indicated that this intermediate potential reversed polarity near rest (Fig. $3 A$ ). In eight cells where the reversal potential lay within the range of spontaneous $V_{m}$ fluctuations, MG stimulation during spontaneous depolarizations and hyperpolarizations (Figs. $2 B, 3 B$ ) demonstrated reversal of this potential at $-56 \pm 1.2 \mathrm{mV}$ (Fig. $2 B$, middle panel). This reversal potential is intermediate to those of the EPSP and I-IPSP, and clearly differentiates the three potentials. Thus, the intermediate potential likely represents a distinct synaptic potential, and is most likely a $\mathrm{Cl}^{-}$-mediated IPSP (Krnjevic and Schwartz, 1967; Avoli, 1986; Douglas and Martin, 1991). While $V_{m}$ fluctuations in vivo make direct comparisons to in vitro data difficult, the three synaptic potentials observed here closely resemble, in terms of latency, time course, and voltage dependence, the short-latency EPSP, rapid e-IPSP, and long-lasting 1-IPSP elicited in the in vitro auditory cortex (Cox et al., 1992). For the remainder of this report, we will refer to the synaptic potentials in vivo and in vitro using the same designations.

MG stimulation during different phases of the $V_{m}$ fluctuation showed that spontaneous long-lasting hyperpolarizations could sometimes reduce the amplitude of the EPSP, suggesting shunting inhibition. This increased the variability of the EPSP amplitude, and weakened the correlation of EPSP amplitude with $V_{m}$ (Fig. 2B). For the cell in Figure $2 B$ (middle panel), while the correlation coefficient for the change of EPSP amplitude with $V_{m}(r=0.538)$ was statistically significant $(p<0.02)$, it was less than that of the e-IPSP $(r=0.907)$ or the 1-IPSP $(r=0.919)$. In fact, in only 4 of 11 cells recorded with $\mathrm{K}^{+}$-based pipette solutions was the EPSP correlation coefficient significantly different from zero, and in these cases it averaged $0.772 \pm 0.093$ ( $t$ test, $p<0.02$; an example of a cell with a nonsignificant correlation coefficient is shown in Fig. $6 A$ ). If the spontaneous hyperpolarization can shunt the EPSP, then it should be associated with a decreased input resistance. Estimates of $R_{i}$ based on responses to brief, hyperpolarizing current pulses varied $50 \%$ or more during robust spontaneous fluctuations in $\mathrm{K}^{+}$-based pipette solutions, and were lowest during spontaneous hyperpolarizations (Fig. $2 B$, right panel). Since the most consistent measurement of $R_{i}$ was obtained during the long-lasting hyperpolarization, this value was designated as $100 \%$; the maximum change in $R_{i}$ during the fluctuations then averaged $192 \pm 26 \%$ $(n=11)$. These data indicate that the long-lasting hyperpolarization is associated with a conductance increase that can reduce the magnitude of the thalamocortical EPSP by electrical shunting. 

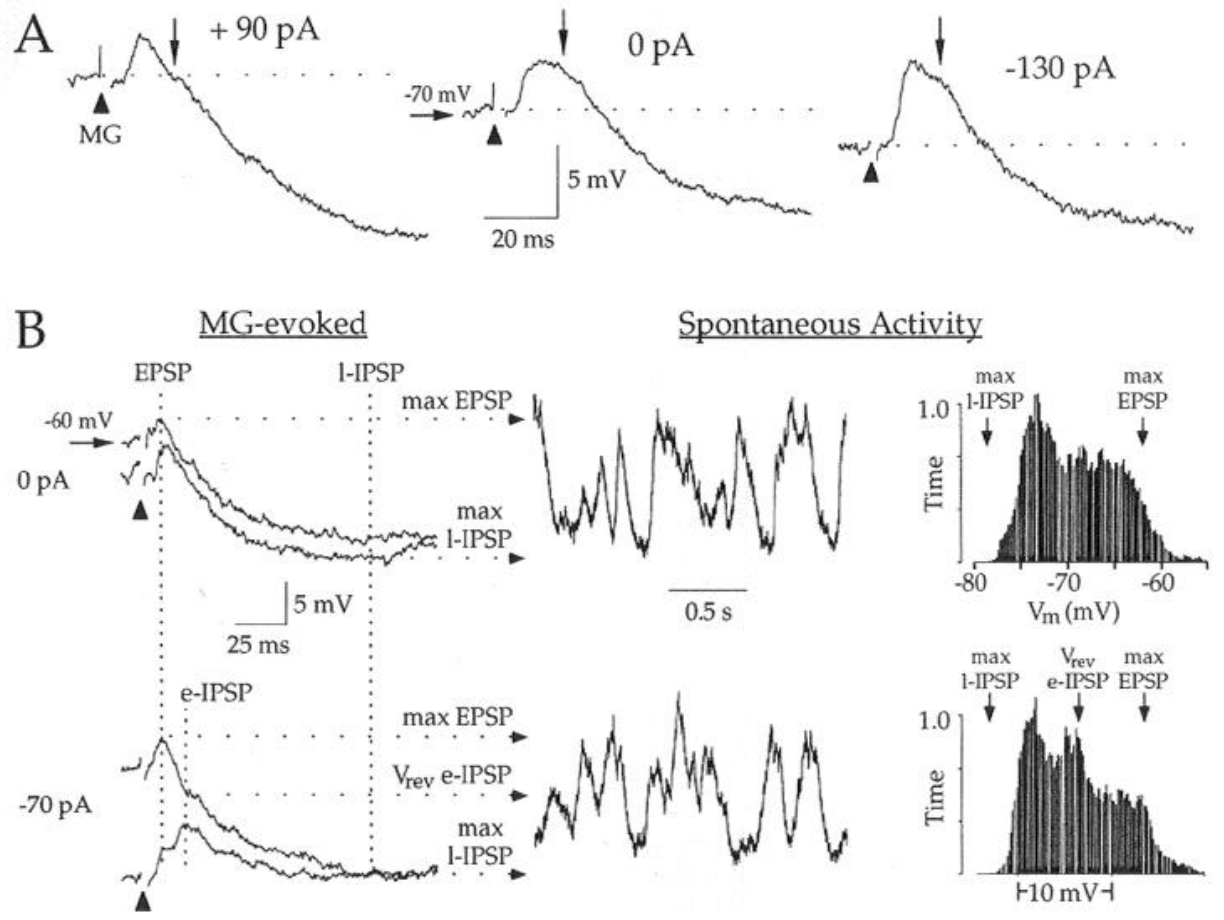

Figure 3. Within-cell comparison of MG-evoked and spontaneous potentials in $\mathrm{K}^{+}$-based recording solution. A, Averages of two or three MGelicited synaptic responses during passage of three different current levels through the recording electrode indicate presence of EPSP, e-IPSP, and 1-IPSP. Reversal of e-IPSP (arrows at $20 \mathrm{msec}$ latency indicate approximate e-IPSP peak) is clearly seen by comparing responses during steady current; during $0 \mathrm{pA}$ or $-130 \mathrm{pA}$ current the e-IPSP is depolarizing, leading to a long-duration compound EPSP/e-IPSP. $B$, Same cell as $A$; comparison of synaptic responses (left traces are individual records, not averages) to spontaneous $V_{m}$ fluctuations (middle) and $V_{m}$ versus time histograms (right; derived from $15 \mathrm{sec}$ of spontaneous activity), at rest $(0 \mathrm{pA}$, top records), and during steady hyperpolarization ( $-70 \mathrm{pA}$, bottom records). These records were collected after 15-17 min of recording in the $\mathrm{K}^{+}$-based solution. Note the correspondence between the maximum spontaneous and EPSP depolarizations and maximum spontaneous and l-IPSP hyperpolarizations. During passage of $-70 \mathrm{pA}$ (bottom records), the approximate e-IPSP reversal potential $\left(V_{\text {rev }}\right)$ is also evident, and corresponds to an intermediate level of spontaneous fluctuations. These intermediate fluctuations produced a peak in the $V_{m}$ versus time histogram near the e-IPSP reversal value.

\section{Within-cell comparison of spontaneous and $M G$-evoked potentials}

All three MG-evoked synaptic potentials correlated with specific aspects of spontaneous $V_{m}$ fluctuations (Fig. $3 B$ ). Subthreshold synaptic and spontaneous potentials were compared within the same neuron in 16 cases. The MG-evoked EPSP depolarized the membrane potential to a maximum level of $-52.8 \pm 2.7$ $\mathrm{mV}$, which was not different from the maximum spontaneous depolarization of $-52.3 \pm 2.7 \mathrm{mV}$ (paired $t$ test, two-tail, $p>$ 0.05 ). Similarly, the l-IPSP hyperpolarized the membrane potential to $-73.8 \pm 2.3 \mathrm{mV}$, and the spontaneous long-lasting hyperpolarization was to $-73.5 \pm 2.1 \mathrm{mV}(p>0.05)$. In general, the difference between evoked and spontaneous maximum depolarizations was about 4-6 mV, whereas evoked and spontaneous maximum hyperpolarizations differed by less than $3 \mathrm{mV}$. Passage of steady depolarizing or hyperpolarizing current altered both spontaneous and evoked responses similarly. In Figure $3 B$, for example, the maximum and minimum membrane potentials achieved by synaptic potentials (left panels) and spontaneous activity (middle panels) were similar (comparison made in right panels) during passage of $0 \mathrm{pA}$ or $-70 \mathrm{pA}$ steady current. Together, these data indicate that the EPSP and l-IPSP likely share ionic flux characteristics with the spontaneous depolarizations and long-lasting hyperpolarizations, respectively.

The e-IPSP was more difficult to correlate with spontaneous fluctuations since its reversal potential generally lay within the range of spontaneous fluctuations. The resulting spontaneous potentials would be of small amplitude and of either polarity, and therefore difficult to detect directly. Our approach was to identify the e-IPSP in evoked responses, and examine $V_{m}$ versus time histograms of spontaneous activity for peaks near the e-IPSP reversal potential. The assumption was that if spontaneous potentials were numerous, they could create a peak in the histogram regardless of their polarity. The e-IPSP reversal potential lay near a distinct peak in the $V_{m}$ versus time histogram in three neurons, aided at times by the passage of steady current through the electrode (lower panels in Fig. 3B). More commonly, spontaneous potentials near the e-IPSP reversal potential combined with spontaneous depolarizations to produce a single, broad peak at a depolarized level, distinct from the single peak at hyperpolarized levels produced by the long-lasting hyperpolarization (e.g., peaks in histograms seen in Figs. $1 B, 5 B ; n=7$ ). In any case, the presence of a peak, or a portion of a peak, near the e-IPSP reversal potential is consistent with spontaneous fluctuations being driven to that potential, and supports the idea that each of the three synaptic potentials have analogs in spontaneous activity.

These within-cell comparisons suggest that the same ion species responsible for the EPSP, e-IPSP, and 1-IPSP may generate spontaneous $V_{m}$ fluctuations. As described above, the MGevoked e-IPSP and 1-IPSP are likely due to $\mathrm{Cl}^{-}$and $\mathrm{K}^{+}$conductances, respectively. We therefore hypothesize that slow, spontaneous $\mathrm{V}_{\mathrm{m}}$ fluctuations consist, at least partly, of intermingled rapid depolarizations, rapid $\mathrm{Cl}^{-}$-mediated hyperpolarizations, and long-lasting $\mathrm{K}^{+}$-mediated hyperpolarizations. The long- 
lasting hyperpolarizations could recur at regular intervals, thereby setting the rhythm of slow-wave activity. Since the longlasting hyperpolarizations appeared to be suppressed by NBmediated cholinergic actions (Metherate et al., 1992; Metherate and Ashe, 1993), it was relevant to extend the present study to include the effects of NB stimulation.

\section{NB-mediated modification of spontaneous $\mathrm{V}_{\mathrm{m}}$ fluctuations}

NB stimulation modified $V_{m}$ fluctuations from large-amplitude, slow fluctuations to smaller-amplitude, higher-frequency fluctuations (Fig. $4 ; n=7$ of 8 neurons), as demonstrated previously in sharp microelectrode recordings and attributed to activation of cortical muscarinic cholinergic receptors (Metherate et al., 1992). Cells recovered from the cffects of NB stimulation within 2-10 sec. While NB stimulation resulted in a depolarization of the average membrane potential, in fact, the maximum level of depolarization attained by $V_{m}$ fluctuations following NB stimulation was similar to or less than that preceding NB stimulation. Note that $V_{m}$ fluctuations following NB stimulation appeared to resemble control $V_{m}$ fluctuations during depolarized phases of the slow-wave fluctuations, that is, between occurrences of the long-lasting hyperpolarizations (Fig. $4 A$, insets; see also Fig. 3 of Metherate et al., 1992). As indicated by $V_{m}$ versus time histograms, NB stimulation produced a shift away from hyperpolarized values, increased the time spent at intermediate $V_{m}$ values, and reduced the maximum level of depolarization (Fig. $4 B$, bottom). The most parsimonious explanation for these data is that NB stimulation results in the blockade of spontaneous, long-lasting hyperpolarizations. This could directly produce a shift away from hyperpolarized values, and indirectly reduce the maximum depolarization by preventing the "rebound" excitation that often follows long-lasting hyperpolarizations in neocortex (Steriade, 1984; Friedman and Gutnick, 1987; Foehring and Waters, 1991).

Given the muscarinic nature of NB actions (Buzsaki et al., 1988; Metherate et al., 1992) and the hypothesized ionic basis of $V_{m}$ fluctuations, we further propose that $N B$-mediated modification of $\mathrm{V}_{\mathrm{m}}$ fluctuations results from muscarinic blockade of spontaneous $K^{+}$currents, allowing intermixed rapid depolarizations and $\mathrm{Cl}^{-}$-mediated hyperpolarizations to continue uninterrupted. Two tests of our hypotheses are immediately apparent: first, pharmacological blockade of $\mathbf{K}^{+}$channels should produce effects similar to those of NB stimulation; second, blockade of $\mathrm{Cl}^{-}$channels should produce predictable modifications of spontaneous and NB-mediated effects, since $\mathrm{Cl}^{-}$currents might normally act to retard depolarization. Since the WCR technique allows rapid diffusion of pharmacological agents into the cell interior (Pusch and Neher, 1988), we attempted to test these hypotheses through modifications of the WCR pipette solutions.

\section{Effects of intracellular $\mathrm{Cs}^{+}$on spontaneous, $\mathrm{MG}$-evoked, and $N B$-evoked $\mathrm{V}_{\mathrm{m}}$ fluctuations}

Substitution of $\mathrm{Cs}^{+}$for $\mathrm{K}^{+}$in the pipette solution rapidly produced striking changes in neural activity. Within seconds of recording, $\mathrm{Cs}^{+}$began to modify the shape of spontaneous action potentials. The earliest modification was an increase in spike width and the appearance of a shoulder during the falling phase of the action potential (Fig. $5 A$, left), confirming blockade of $\mathrm{K}^{+}$ channels (Bezanilla and Armstrong, 1972; Puil and Werman, 1981). Invariably, after 1-3 min of additional recording time, a large-amplitude, all-or-none depolarizing potential often could
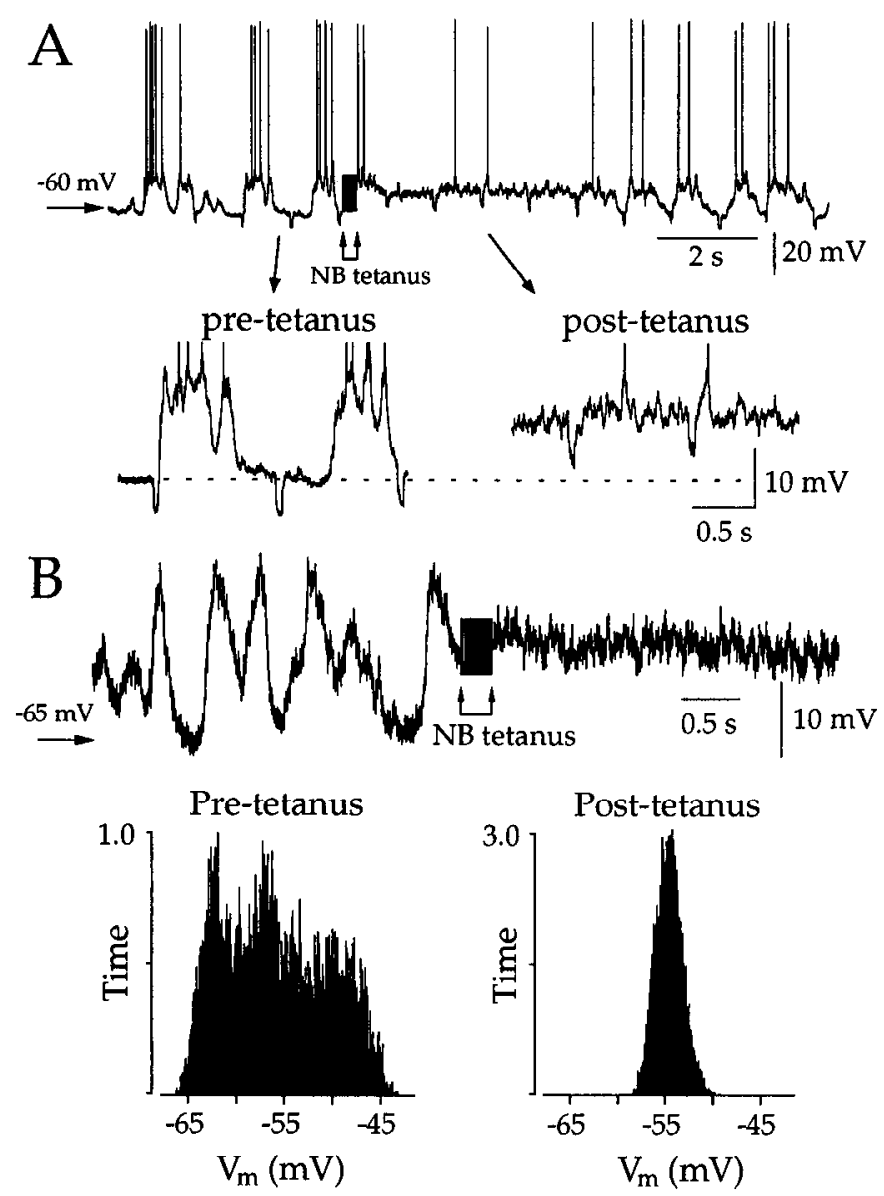

Figure 4. NB stimulation modified $V_{m}$ fluctuations in $\mathrm{K}^{+}$-based recording solutions. $A$, NB stimulation ( 60 pulses at $200 / \mathrm{sec}, 250 \mu \mathrm{A}$ ) modified fluctuations from large-amplitude, slow fluctuations to smallamplitude, rapid fluctuations. Abrupt negative deflections at $1 / \mathrm{sec}$ throughout record are responses to current pulses $(100 \mathrm{pA}, 50 \mathrm{msec})$. Note that frequency of spike discharge did not increase during NBmediated effect, indicating that the NB effect is not strictly excitatory. However, NB stimulation did eliminate long-lasting, spontaneous hyperpolarizations. The remaining rapid fluctuations resembled those seen during depolarized phases of pretetanus activity (compare insets, preand post-tetanus). Effect of NB stimulation dissipated in several seconds. $B$, NB-mediated modification of fluctuations is quantified in $V_{m}$ versus time histograms for a different cell in which fluctuations were entirely subthreshold. Pretetanus histogram depicts fluctuations spanning a 20 $\mathrm{mV}$ range, with peaks indicating increased activity at hyperpolarized and intermediate $V_{m}$ values. After NB stimulation (60 pulses, $200 / \mathrm{sec}$, $250 \mu \mathrm{A}$ ), the rapid $V_{m}$ fluctuations produced a histogram with a single peak centered near $-55 \mathrm{mV}$ (note change in ordinate scale). In addition to the elimination of hyperpolarized values due to blockade of the longlasting hyperpolarization, note that the maximum depolarization after NB stimulation (about $-50 \mathrm{mV}$ ) is less than that before NB stimulation (about $-45 \mathrm{mV}$ ). The effects of NB stimulation dissipated over 5-10 $\sec$ (not shown).

be seen arising from the spike shoulder, or following nearly complete spike repolarization (Fig. $5 A$, asterisk; see also Fig. $7 A$ ). The all-or-none depolarizing afterpotential appeared following many spikes, but not each one (see Fig. 7A), and may reflect dendritic $\mathrm{Ca}^{2+}$ spikes (Wong et al., 1979; Llinas and Yarom, 1981; Amitai et al., 1993).

Modifications of spontaneous $V_{m}$ fluctuations were apparent soon after the changes in spike waveform. After 3-9 min of recording with $\mathrm{Cs}^{+}$, the long-lasting hyperpolarizations were clearly reduced in amplitude and duration (Fig. $5 B$, left panels; 

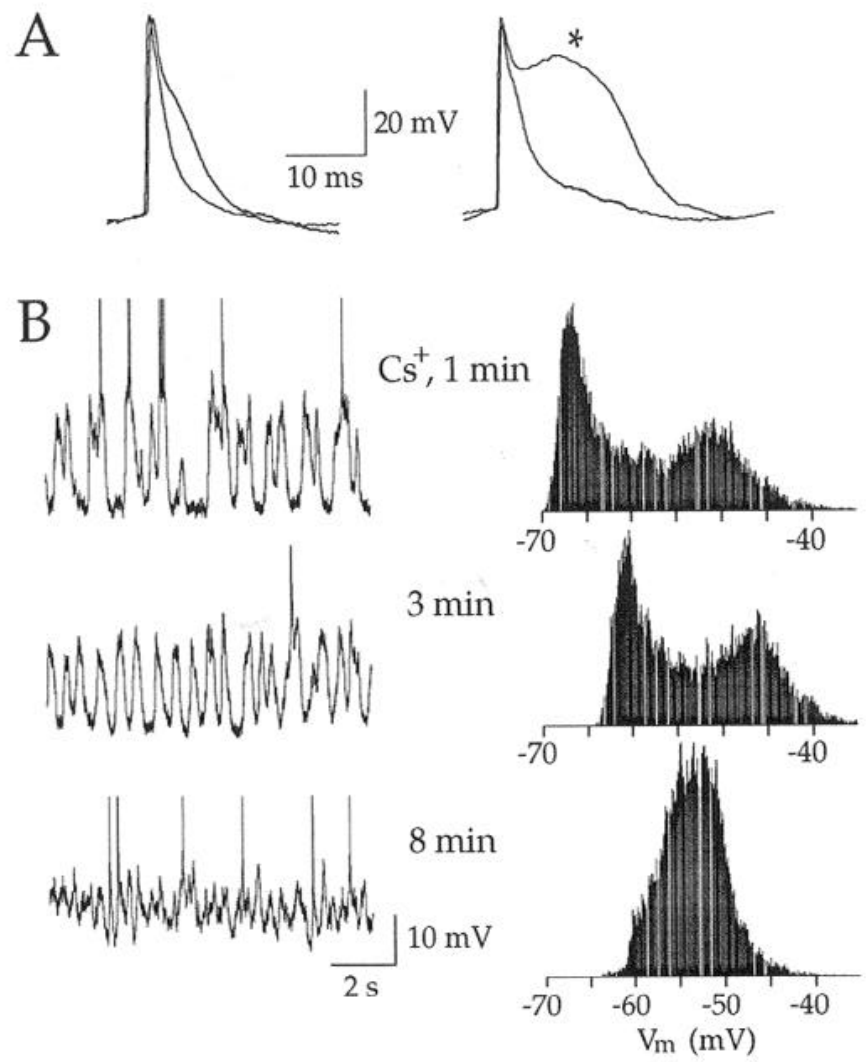

Figure 5. Effects of intracellular $\mathrm{Cs}^{+}$on action potential waveform and spontaneous $V_{m}$ fluctuations. $A$, Within $1 \mathrm{~min}$ of recording with $\mathrm{Cs}^{+}$, spontaneous action potentials were of longer duration than those in $\mathrm{K}^{+}$based solutions and sometimes displayed a shoulder during repolarization (left panel). After 1-3 min (right panel), spikes with falling-phase shoulders were common, and these often gave rise to an all-or-none depolarizing afterpotential (asterisk). B, Over somewhat longer time periods, $\mathrm{Cs}^{+}$effectively blocked long-lasting hyperpolarizations. Initially, this neuron displayed robust $V_{m}$ fluctuations over an approximately $30 \mathrm{mV}$ range (activity at $1 \mathrm{~min}$, left panel; spikes truncated throughout $B$ ), with activity at both hyperpolarized and depolarized levels resulting in peaks in the $V_{m}$ versus time histogram (right panel). Cesium gradually reduced the amplitude and duration of long-lasting hyperpolarizations (activity at $3 \mathrm{~min}$ ) until they were completely blocked $(8 \mathrm{~min})$. Note that activity at $8 \mathrm{~min}$ produced a single, intermediate peak in the $V_{m}$ versus time histogram, like that produced by NB stimulation, with reduced activity at both hyperpolarized and depolarized levels. Note also that the rate of spontaneous spike discharge remained relatively unchanged.

$n=8$ ), an effect that was reflected in $V_{m}$ versus time histograms (Fig. 5B, right panels). The maximum level of spontaneous depolarizations remained relatively unaltered, or was slightly reduced. These data indicate that spontaneous, long-lasting hyperpolarizations are likely mediated by $\mathrm{K}^{+}$currents. Qualitatively, the changes in spontaneous fluctuations produced by $\mathrm{Cs}^{+}$(Fig. $5 B$ ) resembled those produced by NB stimulation (Fig. 4B). These data suggest that both $\mathrm{Cs}^{+}$and $\mathrm{NB}$ stimulation may act to block $\mathrm{K}^{+}$-mediated, long-lasting hyperpolarizations.

Cesium-induced modifications of thalamic-evoked EPSPs provided further information regarding spontaneous $V_{m}$ fluctuations. Even during partial reduction of the spontaneous hyperpolarizations, $\mathrm{Cs}^{+}$effectively reduced electrical shunting of the MG-evoked EPSP (Fig. 6B). In contrast to data obtained with $\mathrm{K}^{+}$-based solutions (Figs. $2 B, 6 A$ ), the correlation of EPSP magnitude with $V_{m}$ was highly significant in 9 of 10 neurons ( $p$ $<0.01$; mean correlation coefficient $r=0.926 \pm 0.013$ ). These findings further indicate that the long-lasting hyperpolarization ordinarily can shunt the thalamocortical EPSP. Note, however, that although $\mathrm{Cs}^{+}$prevented electrical shunting, spontaneous hyperpolarizations remained potentially inhibitory, since, as shown in Figure $6 B$, they still could reduce the peak depolarization attained by EPSPs. Thus, spontaneous hyperpolarizations ordinarily can modify thalamocortical transmission by means of both hyperpolarizing and shunting inhibition.

Effects of $\mathrm{Cs}^{+}$revealed an important distinction between spontaneous, long-lasting hyperpolarizations and the MG-evoked 1-IPSP. When $\mathrm{Cs}^{+}$first suppressed the spontaneous hyperpolarizations, the MG-evoked l-IPSP was generally not reduced; however, after longer periods of time (e.g., $>15-20 \mathrm{~min}$ ), $\mathrm{Cs}^{+}$ suppressed both the spontaneous and MG-evoked potentials. This differential time course of $\mathrm{Cs}^{+}$effects suggests that while both potentials can be reduced by $\mathrm{Cs}^{+}$, they are not the same potential. That is, spontaneous, long-lasting hyperpolarizations are not "spontaneous" 1-IPSPs.

Interactions between $\mathrm{NB}$ and $\mathrm{Cs}^{+}$effects were studied to obtain further information regarding NB actions. During partial reduction of spontaneous hyperpolarizations by $\mathrm{Cs}^{+}$, NB stimulation modified $V_{m}$ fluctuations similarly to NB stimulation in $\mathrm{K}^{+}$-based solutions (Fig. 7Ai, ii; $n=5$ ). However, in the presence of $\mathrm{Cs}^{+}$, NB stimulation now resulted in an increased frequency of all-or-none depolarizing afterpotentials. For the cell in Figure $7 \mathrm{Ai}$, spontaneous spikes preceding the NB tetanus only occasionally displayed all-or-none depolarizing afterpotentials (indicated by asterisks; higher-resolution example at top left). NB stimulation modified $V_{m}$ fluctuations and, in addition, produced a transient increase in the frequency of all-or-none afterpotentials (example at top right). After recovery of $V_{m}$ fluctuations and afterpotential frequency (Fig. 7Aii, pretetanus activity), a longer-duration NB tetanus produced a more robust, longerduration modification of $V_{m}$ fluctuations and, again, an increase in the frequency of depolarizing afterpotentials.

While NB stimulation could modify $V_{m}$ fluctuations during partial $\mathrm{Cs}^{+}$blockade of long-lasting hyperpolarizations (Fig. 7A,B, top record), NB stimulation produced little additional effect following complete $\mathrm{Cs}^{+}$blockade of spontaneous hyperpolarizations (Fig. $7 B$, bottom record; $n=2$ ). These data suggest overlap of $\mathrm{Cs}^{+}$and NB actions onto the same cellular mechanisms.

\section{Effects of intracellular picrotoxin and high $\mathrm{Cl}^{-}$concentrations on spontaneous and $N B$-mediated $\mathrm{V}_{\mathrm{m}}$ fluctuations}

Striking modification of spontaneous and NB-mediated activity occurred during manipulations of $\mathrm{Cl}^{-}$fluxes. Picrotoxin, a GA$\mathrm{BA}_{\mathrm{A}}$ receptor antagonist/ $\mathrm{Cl}^{-}$channel blocker (Sieghart, 1992), also blocks $\mathrm{Cl}^{-}$conductances when applied intracellularly (Akaike et al., 1985; Inomata et al., 1988; Cupello et al., 1991). Picrotoxin $(10 \mu \mathrm{M})$ was therefore added to the $\mathrm{Cs}^{+}$-based recording solution in four cells. In nine other cells, the pipette solution $\mathrm{Cl}^{-}$concentration was increased from control (7 mM) to $12-125 \mathrm{~mm}$, replacing gluconate on an equimolar basis. Increasing intracellular $\mathrm{Cl}^{-}$by $12-125 \mathrm{~mm}$ would depolarize $\mathrm{E}_{\mathrm{Cl}}-$ by $14-77 \mathrm{mV}$, assuming equivalence of the intracellular and intrapipette $\mathrm{Cl}^{-}$concentrations, and an extracellular $\mathrm{Cl}^{-}$concentration of $128 \mathrm{~mm}$ (Hansen, 1985). Spontaneous activity with picrotoxin $(n=3)$ or high $\mathrm{Cl}^{-}$concentrations $(n=6)$ included occasional or frequent large-amplitude depolarizations with bursts (Fig. $8 A$ ). These consisted of a fast spike, followed by allor-none depolarizing afterpotentials and long-duration, repeti- 

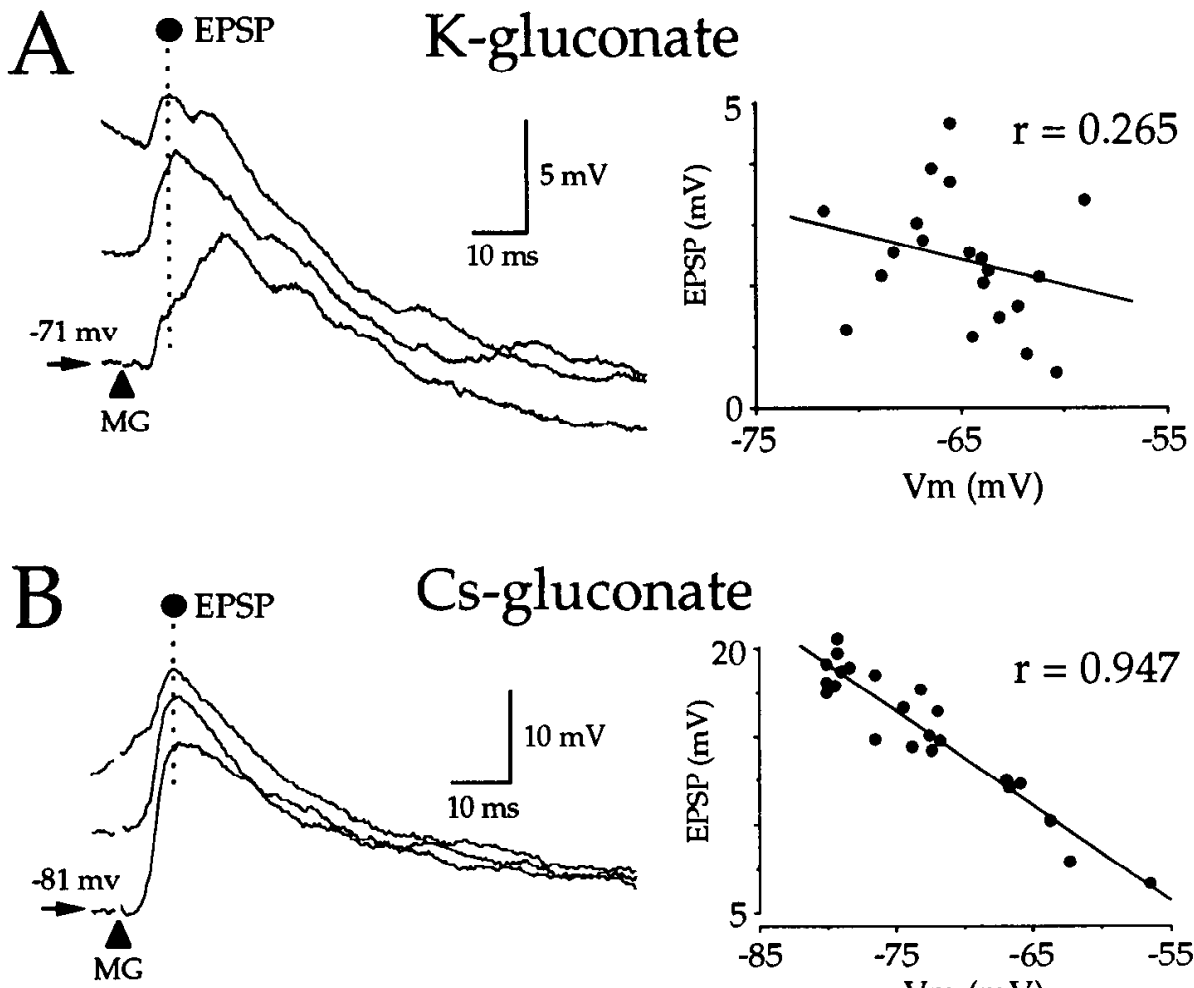

Figure 6. Cesium reduced variability of the thalamocortical EPSP, suggesting blockade of shunting inhibition. $A$, In $\mathrm{K}^{+}$-based pipette solution, stimulating the $\mathrm{MG}(500 \mu \mathrm{A}, 0.5 \mathrm{~Hz})$ during different phases of spontaneous $V_{m}$ fluctuations elicited an EPSP of variable amplitude ( 9 msec latency to peak indicated by dotted line and solid circle). Each trace is the average of two responses at similar potentials. Right panel quantifies change of amplitude with $V_{m}$. Correlation of EPSP amplitude with $V_{m}$ was not significant (correlation coefficient $r=0.265, p>0.1$ ). $B$, Cesium reduced variability of the thalamocortical EPSP in another cell, during partial suppression of long-lasting hyperpolarizations. MG stimulation $(250 \mu \mathrm{A})$ elicited an EPSP (traces on left) whose peak amplitude varied linearly with membrane potential (graph on right; correlation coefficient $r=0.947, p<0.001$ ). Note that while $\mathrm{Cs}^{+}$appears to have reduced shunting (compare Figs. $2 B$, $6 A$ ), EPSPs elicited from hyperpolarized values reached lesser peak values than those elicited from depolarized values (compare traces on left), indicating that spontaneous $V_{\text {,n }}$ fluctuations could still inhibit spike discharge via hyperpolarization. tive discharge of smaller-amplitude spikes with prominent falling-phase shoulders (Fig. $8 A$, inset). Spontaneous bursts never occurred in $\mathrm{K}^{+}$- or $\mathrm{Cs}^{+}$-based solutions alone, and attest to the effectiveness of the $\mathrm{Cl}^{-}$manipulations (cf. Chamberlin and Dingledine, 1988; Avoli et al., 1990).

The addition of picrotoxin to $\mathrm{Cs}^{+}$-based recording solutions resulted in NB stimulation eliciting a large-amplitude depolarization and bursting in each cell tested (Fig. $8 B, C ; n=4$; depolarizations elicited from resting $V_{m}$ ). Note that the cell in Figure $8 B$ (top record) is from the same animal as the cell in Figure $7 A$ (recorded with $\mathrm{Cs}^{+}$, but without picrotoxin), and is stimulated with the same parameters as the longer-duration tetanus (Fig. 7Aii). Thus, the large-amplitude depolarization is not an artifact due to location or intensity of the NB stimulation. The NB-mediated depolarizations and bursts resembled spontaneous bursts, but were of longer duration, enduring for periods of time similar to those of NB actions in control solutions. These data indicate that the action of picrotoxin allows NB stimulation to elicit large-amplitude depolarization, suggesting that $\mathrm{Cl}^{-}$currents normally act to retard excessive depolarization.

An unexpected finding was that the NB-mediated, large-amplitude depolarization was voltage dependent and suggestive of a threshold phenomenon $(n=3)$. In Figure $8 C$, manipulation of $V_{m}$ by passage of steady current through the electrode showed that the large-amplitude depolarization occurred positive to about $-50 \mathrm{mV}$ (amplifier in DCC mode; increasing steady hyperpolarizing current from $i$ to $i v$; dotted lines indicate $-50 \mathrm{mV}$ level for comparison). Note that in Figure $8 \mathrm{Ciii}$, NB stimulation elicited spikes with depolarizing afterpotentials, but did not elicit a large-amplitude depolarization. Thus, the threshold for the large-amplitude depolarization was positive to spike threshold. The threshold for spontaneous large-amplitude depolarizations may have been similarly positive to spike threshold, since spontaneous single spikes often occurred without initiating burst discharge. In one cell recorded with high $\mathrm{Cl}^{-}$concentrations, NB stimulation elicited a large-amplitude depolarization (Fig. $8 B$, bottom record, $12 \mathrm{~mm} \mathrm{Cl}^{-}$), similar to that seen with picrotoxin. While this effect was not apparent in three additional cells recorded with high $\mathrm{Cl}^{-}$concentrations, these cells were hyperpolarized to prevent spontaneous discharge during testing, and were therefore below threshold for the large-amplitude depolarization. Taken together, the effects of picrotoxin and high intracellular $\mathrm{Cl}^{-}$concentrations support the hypothesis that both spontaneous and NB-elicited $V_{m}$ fluctuations normally contain significant $\mathrm{Cl}^{-}$fluxes.

\section{Discussion}

WCRs from auditory cortical neurons in vivo revealed that slow, spontaneous $V_{m}$ fluctuations consisted of rapid depolarizations and hyperpolarizations that were interrupted by slow, long-lasting hyperpolarizations. NB stimulation eliminated the long-lasting hyperpolarizations, leaving the rapid depolarizations and hyperpolarizations relatively unaltered. In terms of time course and voltage dependence, the three components of $V_{m}$ fluctuations resembled MG-evoked EPSPs, $\mathrm{Cl}^{-}$-mediated e-IPSPs, and long-lasting, $\mathrm{K}^{+}$-mediated l-IPSPs, a resemblance that we hypothesize reflects common ionic bases. Modifications of $V_{m}$ fluctuations by pharmacological agents introduced intracellularly via the recording pipette provided experimental support for this hypothesis: $\mathrm{Cs}^{+}$blocked spontaneous long-lasting hyperpolarizations, implicating $\mathrm{K}^{+}$currents in their gencration. This cffect of $\mathrm{Cs}^{+}$resembled the effect of NB stimulation, suggesting an overlap of $\mathrm{Cs}^{+}$and NB actions. The effects of intracellular picrotoxin and high $\mathrm{Cl}^{-}$concentrations provided evidence that rapid $V_{m}$ fluctuations contained significant $\mathrm{Cl}^{-}$components. Both $\mathrm{Cl}^{-}$manipulations led to spontaneous and NB-elicited largeamplitude depolarizations and bursting, indicating that $\mathrm{Cl}^{-}$fluxes normally act to retard excessive depolarization. Together, 

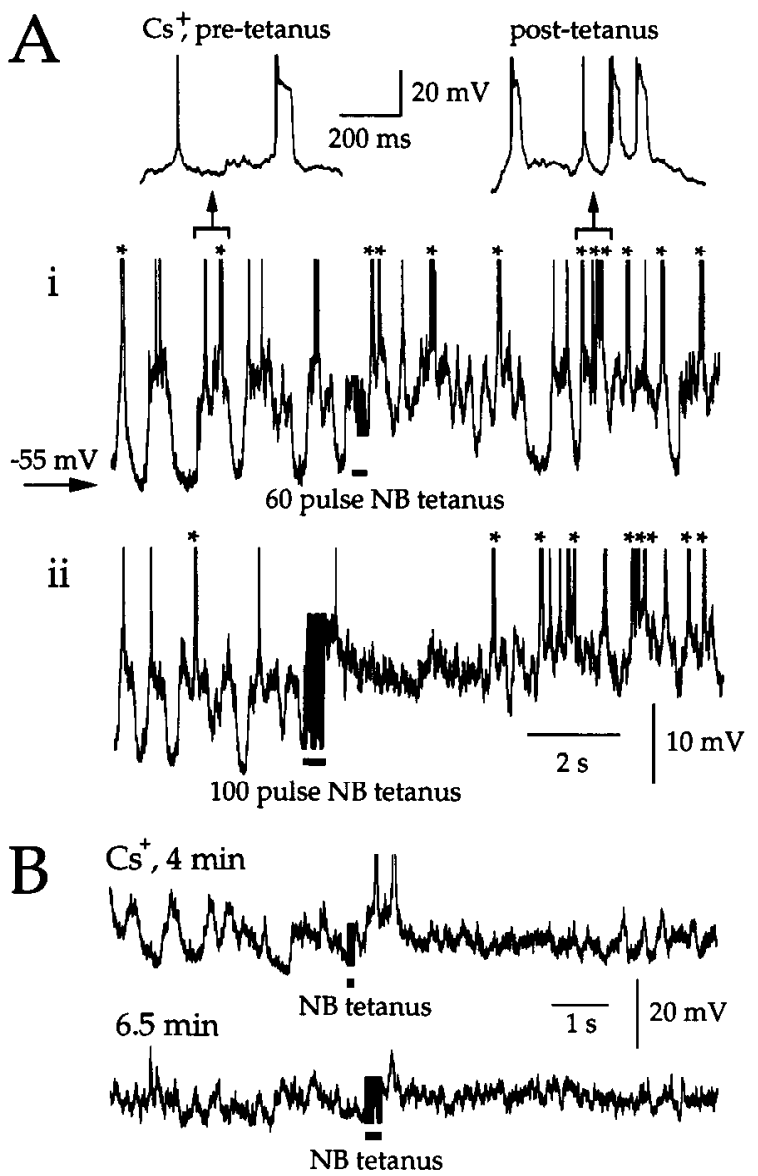

Figure 7. Interactions between $\mathrm{NB}$ and $\mathrm{Cs}^{+}$effects. $A i$, Spontaneous discharge (spikes truncated in $i$ and $i i$ ) during partial $\mathrm{Cs}^{+}$blockade of long-lasting hyperpolarizations contained occasional all-or-none depolarizing afterpotentials (afterpotentials indicated by asterisks; sample activity, including full-amplitude spikes, is enlarged on top left). NB stimulation ( 60 pulses, $200 / \mathrm{sec}, 500 \mu \mathrm{A}$ ) briefly eliminated long-lasting hyperpolarizations, and increased the frequency of all-or-none afterpotentials (increased number of asterisks in $i$, and sample activity enlarged top right). Following recovery of spontaneous hyperpolarizations and afterpotential frequency (pretetanus activity in $i$ ), a longer-duration tetanus (100 pulses) produced a longer-duration change in $V_{m}$ fluctuations and, again, an increase in afterpotential frequency. $B$, In another cell, $\mathrm{Cs}^{+}$had partially suppressed spontaneous long-lasting hyperpolarizations after $4 \mathrm{~min}$, at which point NB stimulation (20 pulses, 200/ sec, $250 \mu \mathrm{A}$ ) transiently further suppressed them, as in $A$ (two spikes truncated). However, when $\mathrm{Cs}^{+}$had completely suppressed spontaneous hyperpolarizations (after $6.5 \mathrm{~min}$, bottom record), neither the same (not shown) nor a longer-duration NB tetanus (60 pulses, bottom record) appreciably modified $V_{m}$ fluctuations further.

these findings indicate that $\mathrm{K}^{+}$and $\mathrm{Cl}^{-}$fluxes form important components of spontaneous $V_{m}$ fluctuations, and that suppression of long-lasting $\mathrm{K}^{+}$fluxes is a critical effect of NB actions.

\section{Spontaneous and MG-evoked $\mathrm{V}_{\mathrm{m}}$ activity}

Since the urethane-anesthetized animal displays an EEG with temporal and pharmacological similarities to slow-wave EEG patterns in undrugged animals (Fox and Armstrong-James, 1986; Armstrong-James and Fox, 1988; Buzsaki et al., 1988; Vanderwolf, 1988; Steriade et al., 1990), it provides a useful tool to study the cellular bases of such macroscopic activity. Previous studies using simultaneous intracellular and extracellular recordings have revealed that $V_{m}$ fluctuations vary in phase with
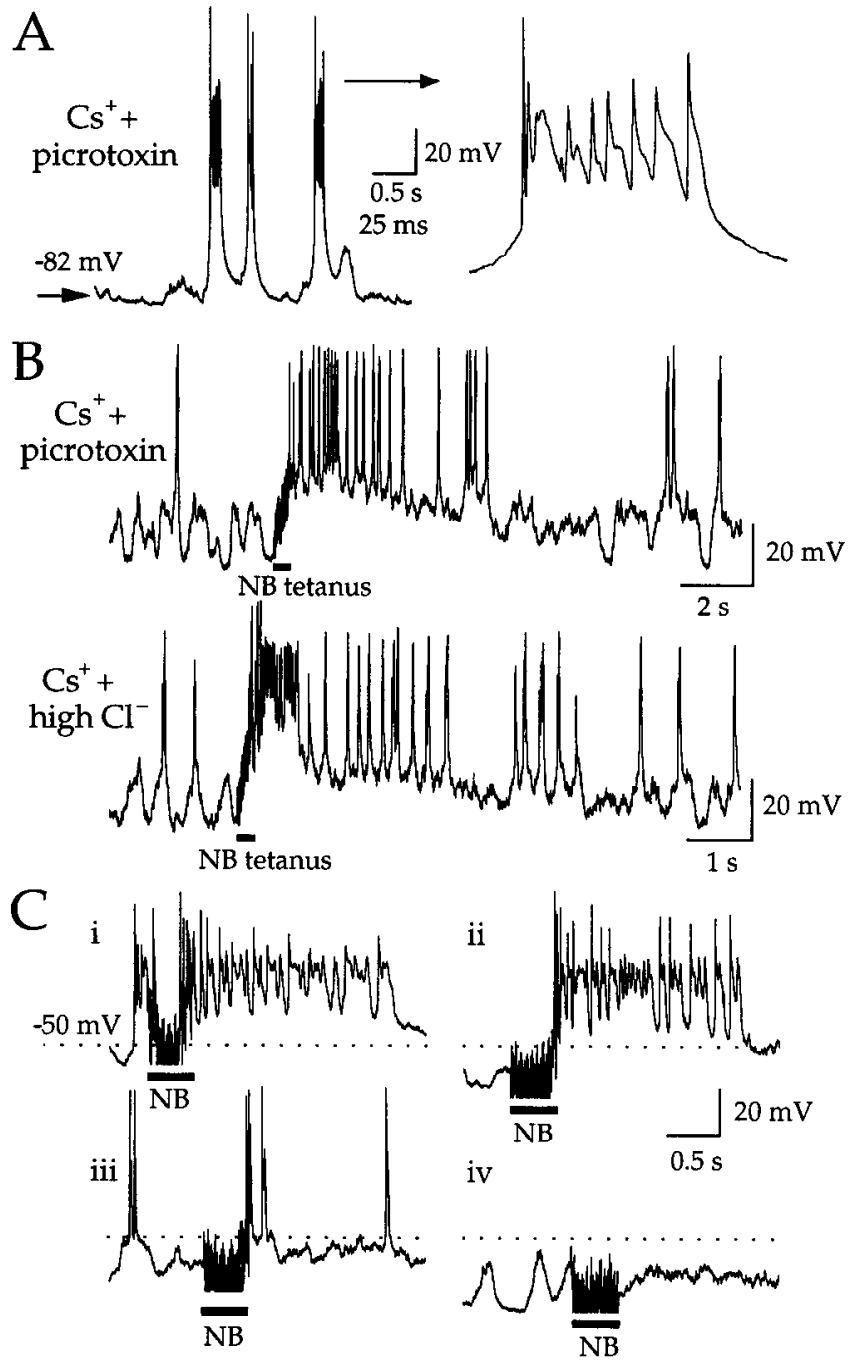

Figure 8. Effects of intracellular picrotoxin or high intracellular $\mathrm{Cl}^{-}$ concentrations on spontaneous and NB-elicited activity. $A$, Spontaneous activity recorded with $\mathrm{Cs}^{+}$and picrotoxin $(10 \mu \mathrm{M})$ in the pipette included large-amplitude depolarizations and bursting. Third burst is shown on the right at faster time scale. Bursts were initiated by a fast spike, and contained all-or-none depolarizing afterpotentials and smaller-amplitude spikes with falling-phase shoulders. $B$, The presence of either picrotoxin $(10 \mu \mathrm{M}$; top record $)$ or high $\mathrm{Cl}^{-}(12 \mathrm{mM}$; bottom record $)$ in the $\mathrm{Cs}^{+}$-based recording solution resulted in NB stimulation eliciting largeamplitude depolarization and bursting. The effects endured for periods of time similar to those of $\mathrm{NB}$ stimulation in $\mathrm{K}^{+}-$based solutions. Neuron recorded with picrotoxin is from the same animal, and is stimulated with the same tetanus parameters as the cell in Figure 7 Aii, indicating that the large-amplitude depolarization was not an artifact resulting from the stimulus locus or intensity. $C$, Voltage dependence of the NBelicited depolarization. Same neuron as in $A$, recorded after $25 \mathrm{~min}$; baseline $V_{r}$ was $-60 \mathrm{mV}$. Amplifier was in DCC mode (switching frequency $10 \mathrm{kHz}$ ) to allow measurement of $V_{m}$ during passage of steady current. Records are of response to NB stimulation during increasing levels of hyperpolarization from $i$ to $i v$ (actual sequence of records was $i v, i i, i$, iii; dotted line at $-50 \mathrm{mV}$, near spike threshold, is to facilitate comparison between records). NB tetanus elicited large-amplitude depolarization and bursting at depolarized levels $(i$ and $i i)$, but not at more hyperpolarized levels ( $i i i$ and $i v$ ). Note in $i i i$ that NB stimulation elicited spikes, but not the large-amplitude depolarization, indicating that the threshold for the large-amplitude depolarization was positive to spike threshold. 
slow-wave and activated EEG patterns (Purpura et al., 1964; Creutzfeldt, 1974; Metherate et al., 1992). Spectral analysis in the present study further supports the correspondence of spontaneous $V_{m}$ fluctuations and the slow-wave EEG. Thus, the present results bear upon cellular and ionic mechanisms of EEG generation. Within this context, an important finding of the present study is that the spontaneous, long-lasting hyperpolarization (that corresponds to slow, surface negative/deep positive EEG waves) is an active conductance, and not simply a passive recovery to baseline following spontaneous depolarizations. This is inferred from the similarity of the spontaneous hyperpolarization's voltage dependence to that of the l-IPSP, its association with an increase in conductance, its ability to shunt the thalamocortical EPSP, and its suppression by $\mathrm{Cs}^{+}$.

WCRs of intracellular potentials in vivo (Pei et al., 1991; Ferster and Jagadeesh, 1992; present results) qualitatively resemble those made with sharp microelectrodes, confirming the validity of this experimental approach. In addition, the EPSP, e-IPSP, and l-IPSP resemble those from a number of neocortical areas in vitro (Connors et al., 1982, 1988; Avoli, 1986; Cox et al., 1992) and in vivo (de Ribaupierre et al., 1972; Creutzfeldt, 1974; Douglas and Martin, 1991). However, in comparing the present data with two previous studies of rat auditory cortex conducted using conventional sharp microelectrodes in vivo and in vitro (Table 1), one sees not only similarities among the three data sets, but also differences that are more clearly interpretable given the attributes particular to each preparation and recording technique. For example, the lower baseline $V_{m}$ values recorded in vivo likely reflect continuous activation of synaptic and intrinsic voltage-dependent processes, and not simply an inherent instability of in vivo recording, since membrane damage due to the recording electrode should lower $R_{i}$. Instead, the greater than threefold higher $R_{i}$ obtained in WCRs, as compared to sharp electrodes in vitro, is evidence of the tight seal between the recording pipette and the cell membrane (Hamill et al., 1981).

The present study demonstrated that thalamocortical transmission does interact with ongoing cortical activity. Specifically, it was seen that spontaneous, long-lasting hyperpolarizations can inhibit the thalamocortical EPSP by both shunting and hyperpolarizing inhibition. While previous studies have indicated that membrane hyperpolarizations induced by sensory stimulation do not shunt thalamocortical inputs (Berman et al., 1991; Ferster and Jagadeesh, 1992), the present findings demonstrate that shunting inhibition does form a component of cortical processing, but one that is mediated by spontaneously active cortical circuits.

These data provide evidence of the unique properties of WCRs that can be exploited experimentally. However, the WCR advantage lies not only in high-resolution recordings, but also in the opportunity to manipulate systematically the intracellular milieu (Pusch and Neher, 1988). Thus, in the present study, we were able to test our hypotheses and manipulate ionic fluxes that contribute to $V_{m}$ fluctuations.

\section{Effects of $\mathrm{NB}$ stimulation and intracellular $\mathrm{Cs}^{+}$}

The NB forms a primary source of neocortical ACh (Rye et al., 1984; Wainer and Mesulam, 1990). Electrical or chemical NB stimulation results in cortical $\mathrm{ACh}$ release and EEG activation (Belardetti et al., 1977; Casamenti et al., 1986; Metherate et al., 1992). NB-mediated activation can be blocked by muscarinic receptor antagonists administered either intracortically or systcmically (Stewart et al., 1984; Buzsaki et al., 1988; Metherate et al., 1992). Thus, cortically released ACh and cortical muscarinic receptors likely mediate the activating effects of NB stimulation; these effects appear to involve suppression of spontaneous, long-lasting hyperpolarizations (Metherate et al., 1992; present results).

Cesium is known to block a number of $\mathrm{K}^{+}$channels (Hille, 1992), and can increase spike duration by reducing the delayedrectifier current (Bezanilla and Armstrong, 1972; Puil and Werman, 1981). This effect in the present study verified the effectiveness of intrapipette $\mathrm{Cs}^{+}$. Thus, the suppression of spontaneous, long-lasting hyperpolarizations in the presence of $\mathrm{Cs}^{+}$can be attributed to blockade of $\mathrm{K}^{+}$channels. Since both $\mathrm{Cs}^{+}$and NB stimulation reduced long-lasting hyperpolarizations, and since NB stimulation was no longer effective following complete $\mathrm{Cs}^{+}$ effects, we suggest a convergence of $\mathrm{Cs}^{+}$and NB actions at $\mathrm{K}^{+}$ channels. It is unlikely, however, that $\mathrm{Cs}^{+}$and $\mathrm{NB}$ actions overlap completely, since (1) NB stimulation never increased spike duration in $\mathrm{K}^{+}$-based solutions, and (2) many $\mathrm{K}^{+}$channels sensitive to blockade by $\mathrm{Cs}^{+}$, including the delayed rectifier (Lancaster and Nicoll, 1987), are not affected by muscarinic actions of ACh. Thus, $\mathrm{Cs}^{+}$and $\mathrm{NB}$ actions may overlap at the $\mathrm{K}^{+}$ current underlying the spontaneous, long-lasting hyperpolarization; this current is unlikely to be the delayed rectifier.

The long-lasting hyperpolarization, while $\mathrm{K}^{+}$mediated, is also not a "spontaneous" 1-IPSP. While $\mathrm{Cs}^{+}$reduced both potentials, spontaneous hyperpolarizations were reduced more effectively and in considerably shorter periods of time. The reduced access of $\mathrm{Cs}^{+}$to the synaptic potential may indicate a distant site of generation. These findings corroborate recent work indicating that while NB stimulation completely eliminates spontaneous hyperpolarizations, only sometimes does it reduce the 1-IPSP, and then only partly (Metherate and Ashe, 1993).

What is the source of the spontaneous, $\mathrm{K}^{+}$-mediated hyperpolarization, if not the delayed rectifier or the l-IPSP? While several $\mathrm{K}^{+}$currents have inappropriate activation characteristics, voltage dependence, time course, or pharmacology, a likely possibility is $I_{\mathrm{K}(\mathrm{Ca})}$, which is activated by $\mathrm{Ca}^{2+}$ influx, has a duration of several hundred milliseconds, and is reduced by $\mathrm{Cs}^{+}$ (Gahwiler and Brown, 1985; Lancaster and Nicoll, 1987; Alger et al., 1990). This current also is blocked by muscarinic actions of ACh (McCormick and Prince, 1986; Lancaster and Nicoll, 1987), making it a plausible target of NB actions (Buzsaki et al., 1988). Influx of $\mathrm{Ca}^{2+}$ during rhythmic, "rebound" depolarizations (e.g., through low-threshold channels; Friedman and Gutnick, 1987; McCormick and Pape, 1990; Foehring and Waters, 1991) could activate $I_{\text {K(Ca) }}$. The contributions of $\mathrm{Ca}^{2+}$ and $\mathrm{Ca}^{2+}$-activated currents to $V_{m}$ fluctuations can be tested, for example, by manipulating $\mathrm{Ca}^{2+}$ buffers in the WCR pipette solution.

The $\mathrm{Cs}^{+}$-induced increase in spike duration was accompanied by the appearance of an all-or-none depolarizing afterpotential. It is puzzling that the afterpotential followed many fast (putative $\mathrm{Na}^{+}$) spikes, but not every one. A possible explanation is that the afterpotentials are $\mathrm{Ca}^{2+}$ spikes that are generated in dendrites, whereas activity at the soma generates $\mathrm{Na}^{+}$spikes alone (Wong et al., 1979; Llinas and Yarom, 1981; Amitai et al., 1993). It is notable that NB stimulation produced an increased frequency of depolarizing afterpotentials, especially since afferents from the NB synapse largely on dendritic shafts (Houser et al., 1985). NB stimulation may increase postsynaptic responsiveness, resulting in dendritic spikes being elicited more frequently, or alternatively, by reducing $\mathrm{K}^{+}$permeability and increasing the 
dendritic length constant may enable additional dendritic spikes to reach the recording site.

\section{Effects of manipulating $\mathrm{Cl}^{-}$fluxes on spontaneous and NB-mediated activity}

Both manipulations of $\mathrm{Cl}^{-}$function, the introduction of intracellular picrotoxin and high intracellular $\mathrm{Cl}^{-}$concentrations, resulted in spontaneous large-amplitude depolarizations and bursting. The likely effect of picrotoxin was to prevent $\mathrm{Cl}^{-}$currents from inhibiting excessive depolarization. Since high intracellular $\mathrm{Cl}^{-}$concentrations would depolarize $\mathrm{E}_{\mathrm{Cl}^{-}}$, the similarity of the resulting effects to those of picrotoxin is instructive. Specifically, moving $\mathrm{E}_{\mathrm{C} 1}$ in a positive direction would produce depolarizing $\mathrm{Cl}^{-}$potentials. While these could still inhibit by shunting, they could also be excitatory if they exceeded spike threshold (Staley, 1992). Note that the estimated shift in $E_{C l}$ for the smallest change in intrapipette $\mathrm{Cl}^{-}$was $14 \mathrm{mV}$, which would move the reversal potential for the e-IPSP $(-56 \mathrm{mV})$ to spike threshold $(-43 \mathrm{mV})$. Depolarizing $\mathrm{E}_{\mathrm{Cl}}$ in vitro also can produce spontaneous, large-amplitude depolarizations and bursting (Chamberlin and Dingledine, 1988; Avoli et al., 1990). Thus, picrotoxin disinhibits excitatory drive, whereas high $\mathrm{Cl}^{-}$ concentrations can enhance excitatory drive; in either case, excessive depolarization and excitation result. Both findings point to significant spontaneous $\mathrm{Cl}^{-}$fluxes that normally act to prevent depolarization.

NB stimulation during picrotoxin blockade also elicited largeamplitude depolarizations and bursting. These responses resembled spontaneous bursts, though of longer duration, and are consistent with the effect of picrotoxin on inhibitory $\mathrm{Cl}^{-}$currents. It is important to note, however, that the resulting depolarization is not solely due to disinhibition of normally occurring excitation. With sufficient steady hyperpolarizing current, to keep $V_{m}$ fluctuations close to or below spike threshold, NB stimulation did not elicit depolarization, and the resulting rapid fluctuations more closely resembled those in control solutions. Since a similar effect occurred with high $\mathrm{Cl}^{-}$concentrations, a voltage-dependent block by picrotoxin does not appear to be responsible. Thus, the large-amplitude depolarization and bursting may involve an additional, voltage-dependent mechanism, one with an activation threshold positive to spike threshold. A plausible mechanism is a high-threshold $\mathrm{Ca}^{2+}$ conductance (Llinas and Yarom, 1981; Sayer et al., 1990). In any case, these data further support the hypothesis that both spontaneous and NB-elicited $V_{m}$ fluctuations contain significant $\mathrm{Cl}^{-}$-mediated components.

\section{Functional relevance of $N B$-mediated actions for cortical information processing}

This study reveals several functions of the NB cholinergic projection to neocortex. Spontaneous, $\mathrm{K}^{+}$-mediated hyperpolarizations reduce the effectiveness of thalamocortical EPSPs, inhibiting both by shunting and by hyperpolarization. NB actions that eliminate long-lasting hyperpolarizations result in higherfidelity responsiveness in cortical neurons, and contribute to facilitation of thalamocortical synaptic transmission (Metherate and Ashe, 1993). Further, NB actions may directly enhance neuronal excitability as well. In the in vitro auditory cortex (Ashe et al., 1992; Metherate et al., 1992), as in other regions (Cole and Nicoll, 1983; Misgeld, 1989), stimulation of cholinergic afferents increases neuronal excitability by increasing $R_{i}$, reducing spikc frequency adaptation, and reducing excitation-in- duced afterhyperpolarization (slow AHP). These muscarinic actions of ACh can directly enhance responsiveness to other inputs. Since both NB and thalamocortical inputs synapse onto dendrites (Houser et al., 1985; Keller and White, 1989), NB synapses are well positioned to facilitate directly responses to afferent inputs, and enhance their influence over neuronal output. Further, $\mathrm{ACh}$ can amplify local changes in intracellular messengers elicited in response to other inputs (Muller and Connor, 1991), potentially producing input-specific modifications such as those hypothesized to underlie some forms of plasticity (Dykes, 1990; Weinberger et al., 1990). All of these mechanisms likely contribute to what is termed the "activated" cortex, and could be critical for processes of neuronal plasticity, learning, and memory.

\section{References}

Akaike N, Hattori K, Oomura Y, Carpenter DO (1985) Bicuculline and picrotoxin block gamma-aminobutyric acid-gated $\mathrm{Cl}^{-}$conductance by different mechanisms. Experientia 41:70-71.

Alger BE, Pitler TA, Williamson A (1990) A prolonged post-tetanic hyperpolarization in rat hippocampal pyramidal cells in vitro. Brain Res 521:118-124.

Amitai Y, Friedman A, Connors BW, Gutnick MJ (1993) Regenerative activity in apical dendrites of pyramidal cells in neocortex. Cereb Cortex 3:26-38.

Armstrong-James M, Fox K (1988) Evidence for a specific role for cortical NMDA receptors in slow-wave sleep. Brain Res 451:189_ 196.

Ashe JH, Cox CL, Metherate R, Jobst E (1992) Cholinergic slow synaptic actions on rat neocortical neurons in vitro. Soc Neurosci Abstr 18:976.

Avoli M (1986) Inhibitory potentials in neurons of the deep layers of the in vitro neocortical slice. Brain Res 370:165-170.

Avoli M, Drapeau P, Perrault J, Pumain R (1990) Epileptiform activity induced by low chloride medium in the CA1 subfield of the hippocampal slice. J Neurophysiol 64:1747-1757.

Belardetti F, Borgia R, Mancia M (1977) Proencephalic mechanisms of ECoG desynchronization in cerveau isole cats. Electroencephalogr Clin Neurophysiol 42:213-235.

Berman NJ, Douglas RJ, Martin KAC, Whitteridge D (1991) Mechanisms of inhibition in cat visual cortex. J Physiol (Lond) 440:697722.

Bezanilla F, Armstrong CM (1972) Negative conductance caused by entry of sodium and cesium ions into the potassium channels of squid axons. J Gen Physiol 60:588-608.

Blanton MG, LoTurco JJ, Kriegstein AR (1989) Whole cell recording from neurons in slices of reptilian and mammalian cerebral cortex. J Neurosci Methods 30:203-210.

Buzsaki G, Bickford RG, Ponomareff G, Thal LJ, Mandel R, Gage FH (1988) Nucleus basalis and thalamic control of neocortical activity in the freely moving rat. J Neurosci 8:4007-4026.

Casamenti F, Deffenu G, Abhamondi A, Pepeu G (1986) Changes in cortical acetylcholine output induced by modulation of the nucleus basalis. Brain Res Bull 16:689-695.

Chamberlin NL, Dingledine R (1988) GABAergic inhibition and the induction of spontaneous epileptiform activity by low chloride and high potassium in the hippocampal slice. Brain Res 445:12-18.

Cole AE, Nicoll RA (1983) Acetylcholine mediates a slow synaptic potential in hippocampal pyramidal cells. Science 221:1299-1301.

Connors BW, Gutnick MJ, Prince DA (1982) Electrophysiological properties of neocortical neurons in vitro. J Neurophysiol 48:13021320.

Connors BW, Malenka RC, Silva LR (1988) Two inhibitory postsynaptic potentials, and $\mathrm{GABA}_{\mathrm{A}}$ and $\mathrm{GABA}_{\mathrm{B}}$ receptor-mediated responses in neocortex of rat and cat. J Physiol (Lond) 406:443-468.

Cox CL, Metherate R, Weinherger NM, Ashe JH (1992) Synaptic potentials and amino acid antagonists in auditory cortex. Brain Res Bull 28:401-410.

Creutzfeldt $O$ (1974) The neuronal generation of the EEG. Amsterdam: Elsevier.

Cupello A, Palm A, Rapallino MV, Hyden H (1991) Can $\mathrm{Cl}^{-}$ions be extruded from a gamma-aminobutyric (GABA)-acceptive nerve cell 
via $\mathrm{GABA}_{\mathrm{A}}$ receptors on the plasma membrane cytoplasmic side? Cell Mol Neurobiol 11:333-346.

de Ribaupierre F, Goldstein MH, Yeni-Komshian G (1972) Intracellular study of the cat's primary auditory cortex. Brain Res 48:185204.

Douglas RJ, Martin KAC (1991) A functional microcircuit for cat visual cortex. J Physiol (Lond) 440:735-769.

Dykes RW (1990) Acetylcholine and neuronal plasticity in somatosensory cortex. In: Brain cholinergic systems (Steriade M, Biesold D, eds), pp 294-313. Oxford: Oxford UP.

Ferster D, Jagadeesh B (1992) EPSP-IPSP interactions in cat visual cortex studied with in vivo whole-cell patch recording. J Neurosci 12: 1262-1274

Foehring RC, Waters RS (1991) Contributions of low-threshold calcium current and anomalous rectifier $\left(I_{h}\right)$ to slow depolarizations underlying burst firing in human neocortical neurons in vitro. Neurosci Lett 124:17-21.

Fox K, Armstrong-James M (1986) The role of the anterior intralaminar nuclei and $N$-methyl-D-aspartate receptors in the generation of spontaneous bursts in rat neocortical neurones. Exp Brain Res 63: 505-518.

Friedman A, Gutnick MJ (1987) Low-threshold calcium electrogencsis in neocortical neurons. Neurosci Lett 81:117-122.

Gahwiler BH, Brown DA (1985) GABA $_{\mathrm{B}}$-receptor-activated K+ current in voltage-clamped $C A 3$ pyramidal cells in hippocampal cultures. Proc Natl Acad Sci USA 82:1558-1562.

Hamill OP, Marty A, Neher E, Sakmann B, Sigworth FJ (1981) Improved patch-clamp techniques for high-resolution current recording from cells and cell-free membrane patches. Pfluegers Arch 391:85100.

Hansen AJ (1985) Effect of anoxia on ion distribution in the brain. Physiol Rev 65:101-148.

Hille B (1992) Ionic channels of excitable membranes. Sunderland, MA: Sinauer.

Houser CR, Crawford GD, Salvaterra PM, Vaughn JE (1985) Immunocytochemical localization of choline acetyltransferase in rat cerebral cortex: a study of cholinergic neurons and synapses. J Comp Neurol 234:17-34.

Inomata N, Tokutomi N, Oyama Y, Akaike N (1988) Intracellular picrotoxin blocks pentobarbital-gated $\mathrm{Cl}^{-}$conductance. Neurosci Res 6:72-75.

Keller A, White EL (1989) Triads: a synaptic network component in the cerebral cortex. Brain Res 496:105-112.

Krnjevic K, Schwartz S (1967) The action of gamma-aminobutyric acid on cortical neurones. Exp Brain Res 3:320-336.

Lancaster B, Nicoll RA (1987) Properties of two calcium-activated hyperpolarizations in rat hippocampal neurones. J Physiol (Lond) 389:187-203.

Llinas R, Yarom Y (1981) Electrophysiology of mammalian inferior olive neurones in vitro. Different types of voltage-dependent ionic conductances. J Physiol (Lond) 315:549-567.

McCormick DA, Pape HC (1990) Properties of a hyperpolarizationactivated cation current and its role in rhythmic oscillation in thalamic relay neurones. J Physiol (Lond) 431:291-318.

McCormick DA, Prince DA (1986) Mechanism of action of acetylcholine in the guinea-pig cerebral cortex in vitro. J Physiol (Lond) 375:169-194.

Metherate R, Ashe JH (1993) Nucleus basalis stimulation facilitates thalamocortical synaptic transmission in rat auditory cortex. Synapse 14:132-143.

Metherate R, Cox CL, Ashe JH (1992) Cellular bases of neocortical activation: modulation of neural oscillations by the nucleus basalis and endogenous acetylcholine. J Neurosci 12:4701-4711.
Misgeld U (1989) Muscarinic slow EPSPs in neostriatal and hippocampal neurons in vitro. Experientia [Suppll 57:104-113.

Muller W, Connor JA (1991) Cholinergic input uncouples $\mathrm{Ca}^{2+}$ changes from $\mathrm{K}^{+}$conductance activation and amplifies intradendritic $\mathrm{Ca}^{2}$ + changes in hippocampal neurons. Neuron 6:901-905.

Paxinos G, Watson C (1986) The rat brain in stereotaxic coordinates. New York: Academic.

Pei X, Volgushev M, Vidyasagar TR, Creutzfeldt OD (1991) Whole cell recording and conductance measurements in cat visual cortex in vivo. Neuroreport 2:485-488.

Poolos NP, Kocsis JD (1990) Dendritic action potentials activated by NMDA receptor-mediated EPSPs in CAl hippocampal pyramidal cells. Brain Res 524:342-346.

Puil E, Werman $R$ (1981) Internal cesium ions block various $\mathrm{K}$ conductances in spinal motor neurons. Can J Physiol Pharmacol 59: $1280-1284$

Purpura DP, Shofer RJ, Musgrave FS (1964) Cortical intracellular potentials during augmenting and recruiting responses. II. Patterns of synaptic activities in pyramidal and nonpyramidal tract neurons. $J$ Neurophysiol 27:133-151.

Pusch M, Neher E (1988) Rates of diffusional exchange between small cells and a measuring patch pipette. Pfluegers Arch 411:204-211.

Rye DB, Wainer BH, Mesulam MM, Mufson EJ, Saper CB (1984) Cortical projections arising from the basal forebrain: a study of cholinergic and noncholinergic components employing combined retrograde tracing and immunohistochemical localization of choline acetyltransferase. Neuroscience 13:627-643.

Sayer RJ, Scwindt PC, Crill WE (1990) High- and low-threshold calcium currents in neurons acutely isolated from rat sensorimotor cortex. Neurosci Lett 120:175-178.

Schwartzkroin PA, Wheal HV (1984) Electrophysiology of epilepsy. London: Academic.

Sieghart W (1992) GABA, receptors: ligand-gated $\mathrm{Cl}^{-}$ion channels modulated by multiple drug-binding sites. Trends Pharmacol Sci 13: $446-450$.

Staley K (1992) Enhancement of the excitatory actions of $G \Lambda B \Lambda$ by barbiturates and benzodiazepines. Neurosci Lett 146:105-107.

Steriade M (1984) The excitatory-inhibitory response sequence in thalamic and neocortical cells: state-related changes and regulatory systems. In: Dynamic aspects of neocortical function (Edelman GM, Gall WE, Cowan WM, eds), pp 107-157. New York: Wiley.

Steriade M, Gloor P, Llinas RR, da Silva FHL, Mesulam M-M (1990) Basic mechanisms of cerebral rhythmic activities. Electroencephalogr Clin Neurophysiol 76:481-508.

Stewart DJ, Macfabe DF, Vanderwolf CH (1984) Cholinergic activation of the electroencephalogram: role of the substantia innominata and effects of atropine and quinuclidinyl benzilate. Brain Res 322: 219-232.

Vanderwolf CH (1988) Cerebral activity and behavior: control by central cholinergic and serotonergic systems. Int Rev Neurobiol 30: 225-340.

Wainer BH, Mesulam M-M (1990) Ascending cholinergic pathways in the rat brain. In: Brain cholinergic systems (Steriade M, Biesold D, eds), pp 65-119. Oxford: Oxford UP.

Weinberger NM, Ashe JH, Metherate R, McKenna TM, Diamond DM, Bakin J (1990) Retuning auditory cortex by learning: a preliminary model of receptive field plasticity. Concepts Neurosci 1:91-132.

Wong RKS, Prince DA, Basbaum AI (1979) Intradendritic recordings from hippocampal pyramidal neurons. Proc Natl Acad Sci USA 76: 986-990. 